\title{
Article \\ Spectral Retrieval of Eucalypt Leaf Biochemical Traits by Inversion of the Fluspect-Cx Model
}

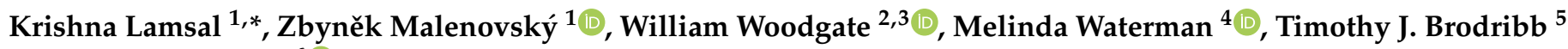 \\ and Jagannath Aryal ${ }^{6}$ (i)
}

check for

updates

Citation: Lamsal, K.; Malenovský, Z.; Woodgate, W.; Waterman, M.; Brodribb, T.J.; Aryal, J. Spectral Retrieval of Eucalypt Leaf Biochemical Traits by Inversion of the Fluspect-Cx Model. Remote Sens. 2022, 14, 567. https://doi.org/ $10.3390 /$ rs 14030567

Academic Editor:

Fernando Pérez-Cabello

Received: 10 December 2021

Accepted: 21 January 2022

Published: 25 January 2022

Publisher's Note: MDPI stays neutral with regard to jurisdictional claims in published maps and institutional affiliations.

Copyright: (C) 2022 by the authors. Licensee MDPI, Basel, Switzerland. This article is an open access article distributed under the terms and conditions of the Creative Commons Attribution (CC BY) license (https:// creativecommons.org/licenses/by/ $4.0 /)$.
1 School of Geography, Planning, and Spatial Sciences, College of Sciences Engineering and Technology, University of Tasmania, Private Bag 76, Hobart, TAS 7001, Australia; zbynek.malenovsky@gmail.com

2 School of Earth and Environmental Sciences, The University of Queensland, St. Lucia, Brisbane, QLD 4072, Australia; w.woodgate@uq.edu.au

3 The Commonwealth Scientific and Industrial Research Organisation (CSIRO), Space and Astronomy, Kensington, WA 6151, Australia

4 School of Earth, Atmospheric and Life Sciences, Faculty of Science, Medicine \& Health, University of Wollongong, Wollongong, NSW 2522, Australia; melindaw@uow.edu.au

5 School of Biological Sciences, University of Tasmania, Private Bag 55, Hobart, TAS 7001, Australia; timothy.brodribb@utas.edu.au

6 Department of Infrastructure Engineering, Faculty of Engineering and Information Technology, The University of Melbourne, Melbourne, VIC 3010, Australia; jagannath.aryal@unimelb.edu.au

* Correspondence: krishna.lamsal@utas.edu.au

Abstract: Leaf biochemical traits indicating early symptoms of plant stress can be assessed using imaging spectroscopy combined with radiative transfer modelling (RTM). In this study, we assessed the potential applicability of the leaf radiative transfer model Fluspect-Cx to simulate optical properties and estimate leaf biochemical traits through inversion of two native Australian eucalypt species: Eucalyptus dalrympleana and E. delegetensis. The comparison of measured and simulated optical properties revealed the necessity to recalibrate the refractive index and specific absorption coefficients of the eucalypt leaves' biochemical constituents. Subsequent validation of the modified Fluspect-Cx showed a closer agreement with the spectral measurements. The average root mean square error (RMSE) of reflectance, transmittance and absorptance values within the wavelength interval of 450-1600 nm was smaller than 1\%. We compared the performance of both the original and recalibrated Fluspect-Cx versions through inversions aiming to simultaneously retrieve all model inputs from leaf optical properties with and without prior information. The inversion of recalibrated Fluspect- $\mathrm{Cx}$ constrained by laboratory-based measurements produced a superior accuracy in estimations of leaf water content $(\mathrm{RMSE}=0.0013 \mathrm{~cm}, \mathrm{NRMSE}=6.55 \%$ ) and dry matter content $\left(\mathrm{RMSE}=0.0036 \mathrm{~g} \cdot \mathrm{cm}^{-2}, \mathrm{NRMSE}=21.28 \%\right.$ ). The estimation accuracies of chlorophyll content $\left(\mathrm{RMSE}=8.46 \mu \mathrm{g} \cdot \mathrm{cm}^{-2}, \mathrm{NRMSE}=24.73 \%\right)$, carotenoid content $\left(\mathrm{RMSE}=3.83 \mu \mathrm{g} \cdot \mathrm{cm}^{-2}\right.$, NRMSE $=30.82 \%)$ and anthocyanin content $\left(\mathrm{RMSE}=1.69 \mu \mathrm{g} \cdot \mathrm{cm}^{-2}, \mathrm{NRMSE}=37.12 \%\right.$ ) were only marginally better than for the inversion without any constraints. Additionally, we investigated the possibility to substitute the prior information derived in the laboratory by non-destructive reflectancebased spectral indices sensitive to the retrieved biochemical traits, resulting in the most accurate estimation of carotenoid content $\left(\mathrm{RMSE}=3.65 \mu \mathrm{g} \cdot \mathrm{cm}^{-2}\right.$, NRMSE $=29 \%$ ). Future coupling of the recalibrated Fluspect with a forest canopy RTM is expected to facilitate retrieval of biophysical traits from spectral air/space-borne image data, allowing for assessing the actual physiological status and health of eucalypt forest canopies.

Keywords: eucalypt; Fluspect; leaf optical properties; biochemical traits; radiative transfer; constrained inversion; optical indices 


\section{Introduction}

Leaf biochemical and structural traits, playing a key role in plant eco-physiological processes, can be used as indicators of a plant stress response [1,2]. Leaf chlorophyll content indicates the light-harvesting potential during plant photosynthetic activity [3], whereas accessory pigments such as carotenoids, specifically xanthophylls and anthocyanins, are involved in protecting plants from harmful excessive solar irradiation [4]. Strong association with plant functions resulted in certain vegetation traits, e.g., amount of chlorophylls and leaf area index (LAI), becoming essential inputs of land-surface models and dynamic biogeochemical models [5], and modelling terrestrial ecosystem functions [6]. Additionally, this association makes plant traits important indicators of environmental disturbances and plant stress. Plants' physiological responses to the changing environmental conditions result in modifications of biophysical parameters and morphology, revealed at both leaf and canopy levels, and subsequent variations in their growth and development. Plants under short-term stress conditions reduce levels of photosynthetic foliar pigments (crown discolouration) [7,8], decrease water content (wilting), and accumulate anthocyanins [9-12]. Long-term stress may change leaf anatomy [13,14], decrease leaf area through defoliation reducing LAI [12], increase canopy temperature due to a lower transpiration rate [15], and reduce leaf size [16-18]. Therefore, accurate estimations of plant traits are crucial for understanding and quantifying vegetation eco-physiological processes and stress responses.

A number of studies have demonstrated the capability of spectroscopy to characterise vegetation traits from optical properties acquired at different spatio-temporal scales [19-25]. Leaf reflectance and transmittance offer an opportunity for non-invasive and rapid quantification of several plant functional traits related to leaf internal anatomical structure and their biochemical composition when using appropriate inversion methods [26-30]. Such a retrieval can be conventionally conducted in three ways: (1) a data-driven empirical/statistical estimation, (2) a mathematical inversion of a physically-based radiative transfer model (RTM), and (3) a combination of (1) and (2), i.e., a hybrid method. The empirical estimation uses mathematical models of statistically significant regressions relating a combination of reflectance and/or transmittance in specific spectral bands to vegetation traits influencing the leaf optical properties [31]. These methods are, however, site-specific and their robustness depends on the quantity and quality of input data used to fit the model. The leaf and canopy radiative transfer models (RTMs), on the other hand, are based on the physical laws describing the interactions and transfer of electromagnetic radiation through a plant leaf and vegetation canopy, respectively [31,32].

Several leaf RTMs were developed to simulate radiative transfer interactions of visible (VIS), near-infrared (NIR), and short-wavelength infrared (SWIR) photons with leaf biochemical and physical components. One of the most widely used RTMs is the PROpriétés SPECTrales (PROSPECT) [27]. PROSPECT simulates directional-hemispherical reflectance and transmittance of leaf adaxial and abaxial sides using the spectrally essential leaf biochemical and morphological traits as inputs. It is built upon the concept of a compact leaf, i.e., a plate radiative transfer theory developed by Allen et al. [33]. Several follow-up versions of PROSPECT were developed to include various light-absorbing constituents [27-29]. Its clone, called Fluspect-B [34], extended the original PROSPECT functionality by additionally simulating leaf chlorophyll fluorescence spectra. The latest version, Fluspect-Cx [35], was enabled to simulate the leaf reflectance dynamics driven by the photo-protective xanthophyll cycle. Aiming to make them as universal as possible, both models were calibrated with measurements acquired for a wide range of biological species. This broad generic calibration, however, limits their accuracy in cases of anatomically and biochemically unique leaves [36]. Consequently, some species-specific versions were created, for instance, PROSPECT versions for different Norway spruce (Picea abies L. Karst.) needle age-cohorts [37]. Therefore, the applicability of the leaf RTMs to species from different geographical and climatic regions of the world requires thorough testing. With pendulous leaves, strong foliage clumping, a semi-transparent canopy and an open forest structure, the evergreen eucalypt forests of Australia are unique and different from 
other vegetation types [38]. Eucalypts populate more than three-quarters of Australian forests [39] and contribute to the exceptional Australian flora biodiversity with a high UNESCO World Heritage value [40]. Previous efforts to estimate leaf traits of Eucalypt species using an RTM inversion were carried out, for example, by Barry et al. [41]. They inverted PROSPECT-4 to estimate chlorophyll $a+b$ content in the Eucalyptus globulus leaf, using the set of specific absorption coefficients (SACs) of leaf absorbers as published in Féret et al. [29]. Similarly, Barry and Newnham [42] quantified chlorophyll and carotenoid pigments in Eucalyptus globulus foliage by inverting PROSPECT-5. These studies were limited only to chlorophyll and carotenoid estimations, while other leaf biochemical traits might be also crucial for assessment of vegetation physiological status, including stress, phenology, and photosynthesis.

An inherent limitation of the operational inversion of leaf RTMs is its ill-posed behaviour. RTM inversion is mathematically ill-posed mainly due to two reasons: (1) the optimal solution is not necessarily unique because different combinations of input parameters (i.e., a set of different solutions) can generate the same leaf spectra [43,44], and (2) the measurement and model uncertainties and assumptions may induce a significant deviation in the optimal solution of the inverse problem [44]. To overcome the ill-posed problem of RTM inversions, strategies such as regularisation techniques and the use of prior information within the inversion merit function were proposed [44]. Several studies [37,45-47] used laboratory-measured leaf biochemical traits as the prior information and reported an improvement in the parameter retrieval accuracy. However, these measurements require a fully equipped laboratory, skilled human resources, and non-negligible operational costs. Although the wet chemical analyses are standardised and accurate, they cannot be carried out in remote locations with limited resources [48] and their destructive nature does not allow for repeated sampling of the same leaf. Numerous studies demonstrated the use of reflectance-based indices in estimating contents of leaf chlorophylls [36,49-56], carotenoids [51,54,57,58], anthocyanins [49,51,54,59], water [60], and dry matter [61]. Hence, to overcome the above-mentioned limitations, we propose replacing the leaf biochemical information with reflectance spectral indices sensitive to the retrieved leaf constituents. Such prior knowledge would allow for repetitive leaf measurements and, subsequently, for long-term in situ monitoring of foliar biochemical changes [62,63].

The overall objective of this study is to investigate the applicability of the Fluspect-Cx model (hereafter referred to as Fluspect) on leaves of two eucalypt species (Eucalyptus dalrympleana and E. delegatensis) to retrieve their biochemical traits from measured optical properties. The study is designed to answer the following research questions: (1) How accurately can Fluspect simulate leaf optical properties of the two eucalypt species? (2) Can Fluspect recalibration improve its forward simulations as well as its inversion estimating the eucalypt leaf biochemical traits acting as model inputs? (3) To what extent can spectral indices sensitive to the retrieved biochemical traits replace the laboratory analytical prior knowledge required for an accurate model inversion? The output of this study is a new Fluspect version for accurate retrieval of eucalypt leaf biophysical parameters from measured optical properties. A future coupling of the new Fluspect with a suitable forest canopy RTM might be employed in the estimation of the same biochemical traits from air/space-borne imaging spectroscopy data, serving as indicators for spatial assessment of the actual forest health.

\section{Materials and Methods}

An overview of the applied methodological approach is outlined in Figure 1. The methodology consists of four phases: (1) acquisition and processing of field measurements, including the leaf sampling design (Section 2.1.1), protocols to measure leaf optical properties (Section 2.1.2), and leaf biochemical parameters (Section 2.1.3), (2) Fluspect performance verification (Section 2.2.1), (3) model recalibration (Section 2.2.2), and (4) validation of the recalibrated model (Section 2.2.3). 


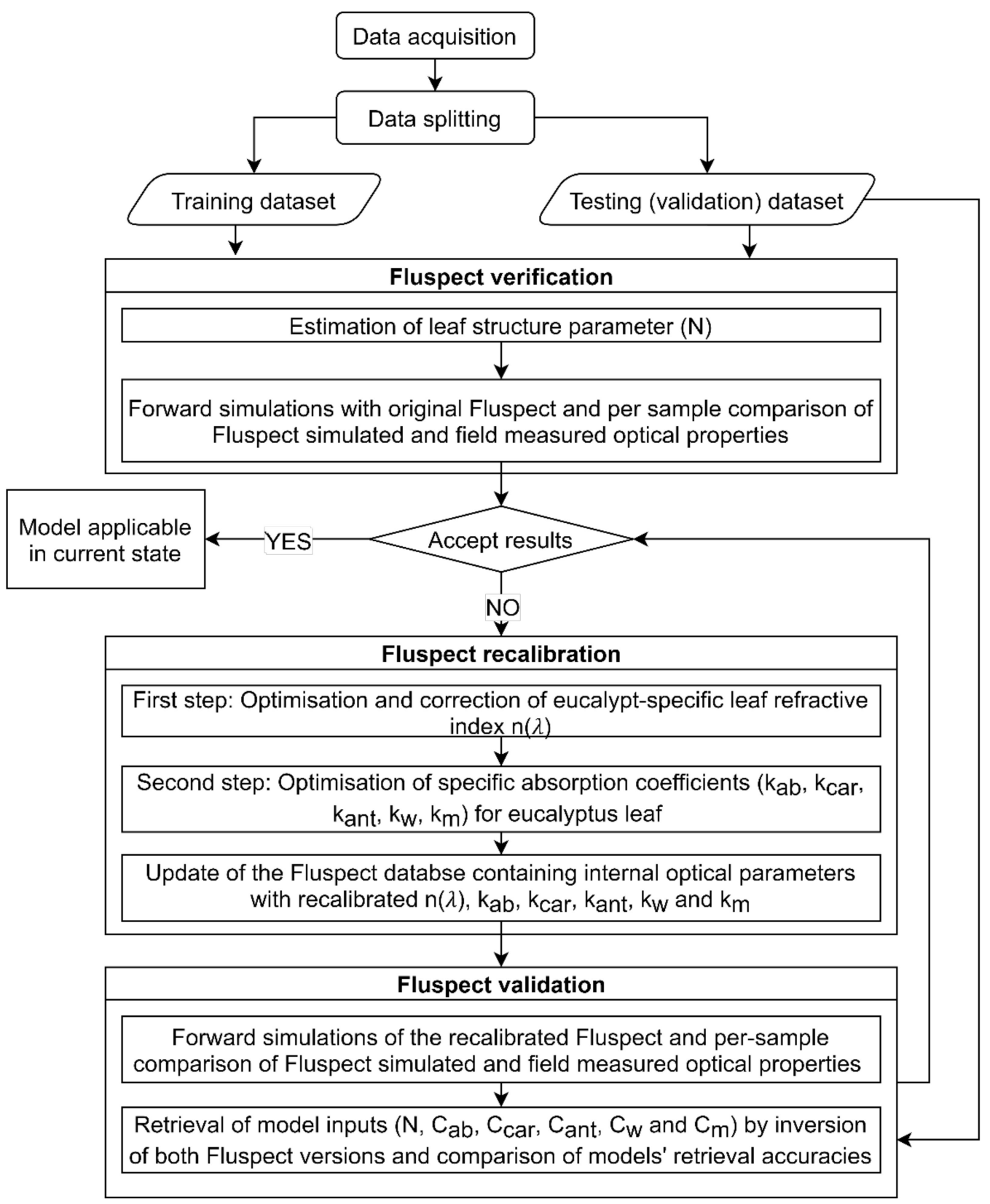

Figure 1. Flowchart illustrating methodological phases and their individual steps $\left(k_{a b}, k_{c a r}, k_{a n t}, k_{w}\right.$ and $k_{m}$ are specific absorption coefficients for chlorophyll $a+b$, carotenoids, anthocyanin, water, and dry matter content, respectively). Abbreviations of leaf constituents' contents: $C_{a b} \sim$ chlorophyll $a+b$, $C_{c a r} \sim$ total carotenoids, $C_{a n t} \sim$ anthocyanins, $C_{w} \sim$ water, and $C_{m} \sim$ dry matter.

\subsection{Acquisition and Processing of Leaf Optical and Biochemical Measurements}

\subsubsection{Study Area and Leaf Sampling Design}

The input datasets of leaf optical properties and corresponding biophysical and biochemical leaf characteristics were acquired through field sampling conducted in forest surrounding the Tumbarumba flux-tower research site (the Bago state forest, south-eastern Australia: $-35.6565^{\circ} \mathrm{N}, 148.1517^{\circ} \mathrm{E}$ ) (Figure 2). Tumbarumba is part of the OzFlux monitoring initiative [64] and a supersite of the Terrestrial Ecosystem Research Network (TERN) [65]. The site is an open multi-aged temperate and wet sclerophyll forest, located between 1200 and $1300 \mathrm{~m}$ above mean sea level and consisting of two dominant eucalypt species: mountain gum (Eucalyptus dalrympleana) and alpine ash (Eucalyptus delegatensis). Height of dominant trees reaches up to $45 \mathrm{~m}$ and the forest understory is a mixture of grasses, herbs, 
and shrubs [66]. The climate is characterised by a mean annual precipitation of around $1500 \mathrm{~mm}$, with a mean annual temperature c. $8.0^{\circ} \mathrm{C}$ [67].
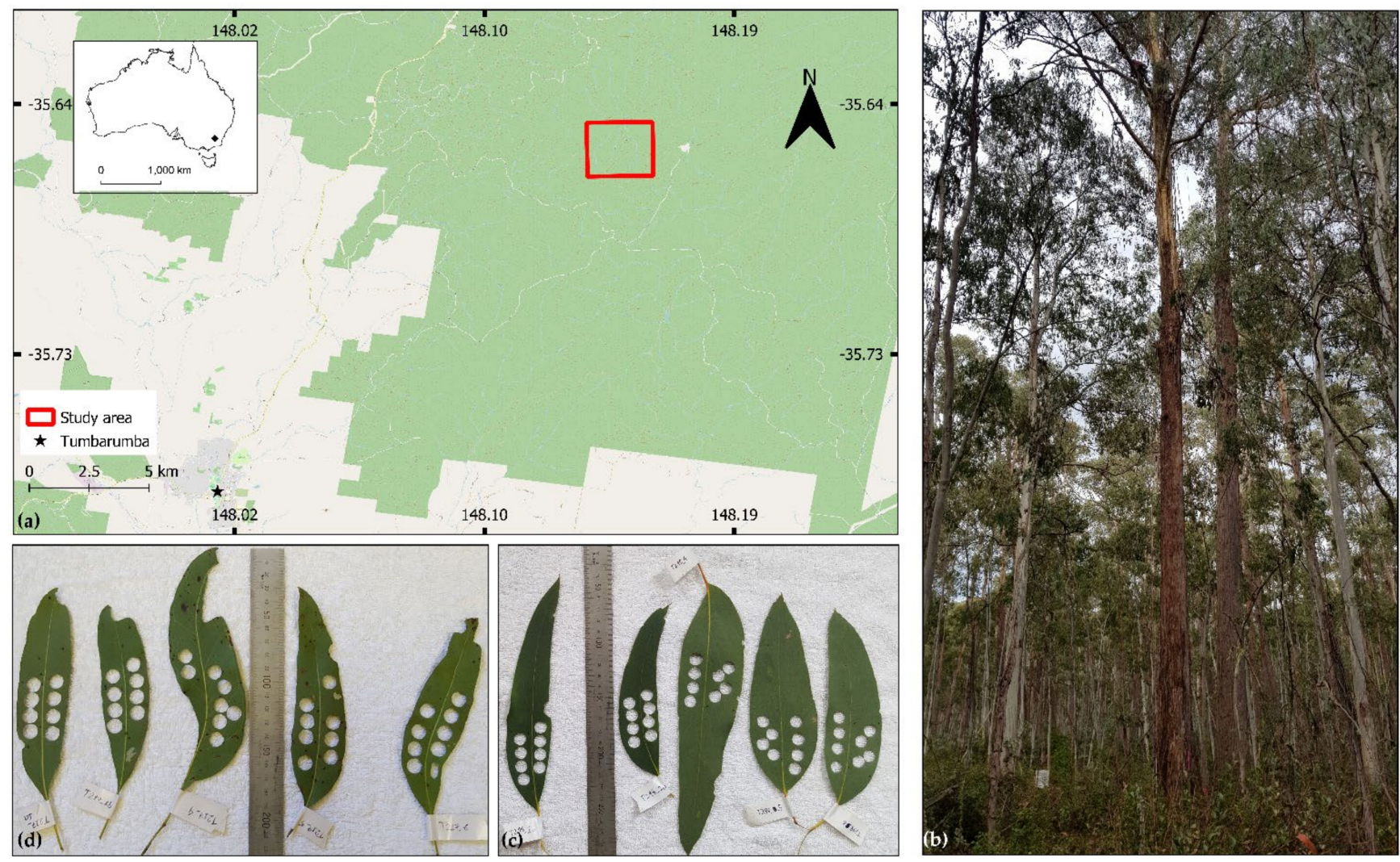

Figure 2. (a) Geographical location of the Tumbarumba study site indicated by the red-coloured rectangle (b) Trees within the study area showing mountain gum (smooth bark at the base) and alpine ash (rough bark at the base) (c) sampled leaves from alpine ash tree and (d) sampled leaves from mountain gum tree.

Eucalypt leaves were sampled from harvested branches originating from trees inside and bordering the 1 ha supersite. The branches were collected by professional tree climbers during the third week of September 2019 and from the ground using an arborist slingshot and throw line at the end of April 2019. A total of 284 leaf samples were collected and measured during the two field campaigns. During the April campaign, tree branches from randomly selected eight mountain gum and ten alpine ash trees were sampled at heights between 1.2 and $39 \mathrm{~m}$ above the ground. This collection was aiming to capture the existing natural variability in the composition and amount of eucalypt foliar pigments by selecting leaf samples of different phenological stages during the leaf flushing [68]. In September, we targeted branches from the upper canopy parts, as this campaign coincided with acquisition of above-canopy image data with a hyperspectral drone system. Tree climbers removed branches from four mountain gum and nine alpine ash trees at four vertical crown heights between 10 and $45 \mathrm{~m}$ above the ground. The branch was cut under water to prevent air cavitation, and collected leaves kept in the water until measured. Four to ten leaf samples were collected from each tree. Both sunlit and shaded leaves were sampled from each branch. The homogeneity in terms of relative content of chlorophyll pigments within the selected leaf blades was assessed with the Minolta SPAD-502 chlorophyll meter. The most chlorophyll content homogeneous part within the selected leaf was indicated with a black marker and used for later optical measurements and destructive laboratory measurements. 


\subsubsection{Field Measurements of Leaf Optical Properties}

Leaf optical properties were measured as soon as feasible after the sample collection but no later than $8 \mathrm{~h}$ after branch detachment unless the sample was placed in the dark for adaptation required for chlorophyll fluorescence measurements (not part of this study). Hemispherical-directional reflectance and transmittance from 400 to $2500 \mathrm{~nm}$ (in radiance units; spectral resolution and sampling of $1 \mathrm{~nm}$ ) were measured in a Li-Cor integrating sphere Li-1800 coupled with a FieldSpec 3 (ASD Inc., Boulder, CO, USA) spectroradiometer. Since eucalypt leaves are of isobilateral morphology [69], i.e., they do not have anatomical differentiation of abaxial and adaxial side, only one side of the leaf was measured. Each leaf was measured at two spots within the previously marked homogeneous area by averaging 50 consecutive spectral scans. The representative optical properties of each sample were computed as a mean of measurements taken at both spots. The hemispherical reflectance and transmittance were computed as:

$$
\begin{aligned}
& \text { Reflectance }=\frac{\left(R_{\text {total }}-L_{s t r}\right)}{L_{r e f}-L_{s t r}} \\
& \text { Transmittance }=\frac{T_{\text {total }}}{L_{r e f}-L_{s t r}}
\end{aligned}
$$

where $R_{\text {total }}$ is the radiation flux reflected from the sample in reflectance mode, $T_{\text {total }}$ is the radiation flux transmitted through the sample in transmittance mode, $L_{s t r}$ is the flux of stray light radiation, and $L_{r e f}$ is the radiation flux reflected from a white reference $\left(\mathrm{BaSO}_{4}\right)$. The spectra between 400 and $450 \mathrm{~nm}$ as well as above $1600 \mathrm{~nm}$ were removed due to the presence of significant noise caused by the sphere reflective coating. A low-level random noise, generated by the spectroradiometer, was eliminated using the SavitzkyGolay smoothing filter [70] of the second polynomial order with a moving wavelength window of $7 \mathrm{~nm}$. After measurement, the homogeneous parts of the leaf were destructively sampled for later biochemical laboratory analyses.

\subsubsection{Laboratory Measurements of Leaf Biochemical Properties}

To determine the leaf dry weight, four leaf blade discs were excised from every sampled leaf using a bore-cork puncher of $9 \mathrm{~mm}$ in diameter. They were placed in a labelled, pre-weighed plastic safe-lock vial and their fresh weight was measured on a laboratory scale with a precision of four decimal places of a gram. The samples were oven-dried at $60{ }^{\circ} \mathrm{C}$ for $48 \mathrm{~h}$ and their dry weight was measured immediately after drying. The dry matter content of sampled leaves was computed as: dry weight in $\mathrm{g} /$ leaf area in $\mathrm{cm}^{2}$. The water content of sampled leaves was then calculated as: (fresh weight-dry weight)/leaf area in $\mathrm{cm}^{2}$. A complementary set of four additional leaf discs was excised from the same leaf, placed in air-locked vials and transported to the laboratory frozen in a liquid nitrogen vessel, where they were stored in a deep freezer at $-80{ }^{\circ} \mathrm{C}$ until further processing.

Contents of chlorophyll $a+b$ and carotenoid pigments were measured from 20-50 mg of fresh weight of leaf cores by adopting the method of Förster et al. [71]. Pigments were extracted into ethyl acetate/acetone ( $0.6 \mathrm{~mL} ; 60: 40$ volume/volume) and analysed via high performance liquid chromatography (HPLC) as explained in Förster et al. [71]. Anthocyanin content was analysed as described in Waterman et al. [72].

The quality screened laboratory and field measurements from April and September 2019 were combined into a single database. The dataset containing directional hemispherical reflectance and transmittance and corresponding leaf biochemical constituents was then randomly split based on 70:30 ratio using the "train_test_split" function of the Scikit-learn python library into a training dataset, devoted to the Fluspect model calibration, and a testing dataset used for independent validation of the recalibrated Fluspect model. To verify that both sets contained a comparable natural variability, i.e., similar dynamic ranges and statistical data distributions, we computed and compared their descriptive statistical 
indicators of leaf biochemical constituents and the leaf mesophyll parameter $\mathrm{N}$ (for more information about $N$, see Section 2.2.1), specifically: minimum, maximum, range, median, mean, and standard deviation. Additionally, the Spearman correlation coefficients were computed among the variables and compared to ensure representativeness of both datasets. Finally, optical properties simulated with the original Fluspect version (Section 2.2.1) were compared with the corresponding measured optical properties to investigate if both datasets provided comparable results and deviations.

\subsection{Fluspect Model Verification, Recalibration, and Validation}

This section presents the methodology for testing the capability of Fluspect to simulate optical properties of the two studied eucalypt species using both training and testing datasets. Since the Fluspect applicability was found to be limited, we also explain our methods applied for recalibration of the leaf refractive index and specific absorption coefficients (SACs) using the training data. Finally, we describe two approaches to validate the performance of the recalibrated model with the test data: (1) a forward modelling and comparison of leaf optical properties, and (2) a model inversion retrieving the input biochemical characteristics from measured optical properties.

\subsubsection{Verification of Fluspect Applicability}

In addition to the laboratory-measured biochemical inputs (for details regarding the model inputs, see Table 1 in Vilfan et al. [35]), the Fluspect performance verification requires the leaf mesophyll structure parameter $(N) . N$ is a conceptual quantity that describes a number of cellular layers, approximated as plates, and their intercellular properties resulting in a leaf optical thickness $[27,73]$. We used leaf reflectance and transmittance of three wavelengths corresponding to maximum reflectance $\left(\lambda_{1}\right)$, maximum transmittance $\left(\lambda_{2}\right)$, and minimum absorptance $\left(\lambda_{3}\right)$, all located in the NIR plateau, and performed the Fluspect inversion to obtain $\mathrm{N}$ for each measured sample according to Féret et al. [29]. The $\mathrm{N}$ retrieval was based on a constrained nonlinear optimisation function (the Matlab built-in function "fmincon") searching for the minimum of the following merit function:

$$
J\left(N, k\left(\lambda_{1}\right) k\left(\lambda_{2}\right), k\left(\lambda_{3}\right)=\sum_{i=1}^{n_{\lambda}}\left(\left(R_{\text {mes }}\left(\lambda_{i}\right)-R_{\text {mod }}\left(N, k\left(\lambda_{i}\right)\right)\right)^{2}+\left(T_{\text {mes }}\left(\lambda_{i}\right)-T_{\text {mod }}\left(N, k\left(\lambda_{i}\right)\right)\right)^{2}\right)\right.
$$

where $n_{\lambda}=3, R_{\text {mes }}\left(\lambda_{i}\right)$ and $T_{\text {mes }}\left(\lambda_{i}\right)$ are the measured reflectance and transmittance at the wavelength $\left(\lambda_{i}\right)$, and $R_{\text {mod }}\left(\lambda_{i}\right)$ and $T_{\text {mod }}\left(\lambda_{i}\right)$ are the respective model simulated values.

Our first hypothesis considered the original Fluspect version by Vilfan et al. [35] to be capable of accurate simulations of eucalypt foliar optical properties within the investigated wavelength range of 450-1600 $\mathrm{nm}$. To test this hypothesis, we compared Fluspect simulated leaf reflectance, transmittance, and absorptance of the training and testing leaf samples with their respective in situ measurements, and computed the following set of statistical indicators: the coefficient of determination $\left(\mathrm{R}^{2}\right)$ of a linear regression, per wavelength spectral root mean square error (RMSE), and its systematic (RMSE $\left.{ }_{\mathrm{S}}\right)$ and unsystematic $\left(\mathrm{RMSE}_{\mathrm{u}}\right.$ ) complementary components as defined in [74]. RMSE $\mathrm{s}$ is a measure of the bias in the investigated model, while the $\mathrm{RMSE}_{\mathrm{u}}$ measures the model precision and is mostly driven by errors in model input data $[30,75]$.

\subsubsection{Recalibration of Fluspect Optical Parameters}

The inaccurate Fluspect performance for the two investigated eucalypt species triggered a two-step recalibration of the refractive index $n(\lambda)$ and the specific absorption coefficients $K_{\text {spe }}(\lambda)$ of leaf biochemical constituents. In the first step, $n(\lambda)$ parameter was recalibrated together with preliminary (first guess) SAC values. The obtained and initial $n(\lambda)$ values were cross-compared to identify possible calibration spectral artifacts. The unrealistic divergence of $n(\lambda)$ values within the measured spectral range were then corrected to produce a plausible $n(\lambda)$ spectrum. In the second step, eucalypt-specific SAC values were retrieved using the newly established $n(\lambda)$. In both steps, the Matlab (The MathWorks, 
Inc., Natick, MA, USA) built-in function "fmincon" was applied to minimise the following merit function:

$J\left(K_{\text {spe,i }}(\lambda), n(\lambda)\right)=\sum_{j}\left(R_{\text {mes }, j}(\lambda)-R_{\text {modd }, j}(k(\lambda), n(\lambda))\right)^{2}+\left(T_{\text {mes }, j}(\lambda)-T_{\text {mod,j }}(k(\lambda), n(\lambda))\right)^{2}$

where

$$
k(\lambda)=\sum_{i} K_{s p e, i}(\lambda) * \frac{C_{i}}{N_{j}}
$$

$k(\lambda)$ is the absorption coefficient of leaf constituents at wavelength $\lambda, C_{i}$ is the concentration of constituent $i, K_{\text {spe,i }}(\lambda)$ is the specific absorption coefficient of the constituent $i$, and $N_{j}$ is the leaf mesophyll structure parameter of the leaf $j$.

\subsubsection{Validation of the Recalibrated Fluspect}

Independent validation of newly recalibrated Fluspect was performed with the testing dataset $(n=85)$ by: (1) comparing the recalibrated Fluspect simulated spectra with the corresponding leaf optical measurements from the field, and (2) assessing the accuracy of model inversions, i.e., quantitative retrievals of model inputs. The Fluspect forward modelling performance was assessed by establishing linear regressions and computing $\mathrm{R}^{2}$ values between measured and simulated directional-hemispherical reflectance, transmittance and absorptance values, and by computing their per wavelength RMSE including RMSEs and RMSEu. The accuracies of the original and the recalibrated Fluspect inversions were assessed through comparison with the corresponding leaf biochemical constituents measured in the laboratory. The model inversions were conducted with two techniques. The first technique searched for the best match between measured and model-simulated reflectance and transmittance values based on the sample spectral information only. The goodness of the fit was quantified with the Matlab "fmincon" function by minimising the merit function:

$M_{i n v}\left(N,\left\{C_{i}\right\} i_{1=p}\right)=\sum_{n=1}^{n_{\lambda}}\left(R_{m e s, \lambda}-R_{m o d, \lambda}\left(N,\left\{C_{i}\right\} i_{1=p}\right)\right)^{2}+\left(T_{m e s, \lambda}-T_{m o d, \lambda}\left(N,\left\{C_{i}\right\} i_{1=p}\right)\right)^{2}$

where $n_{\lambda}$ is the number of spectral bands used, $N$ is the leaf structure parameter, $C_{i}$ is the content of constituent $i$ (i.e., $C_{a b}, C_{c a r}, C_{a n t}, C_{w}$, and $C_{m}$ ), and $\mathrm{p}$ is the number of leaf biochemical constituents. The second technique included constraints in form of a priori information of the retrieved parameters and the uncertainties associated with $R_{m e s, \lambda}$ and $T_{m e s, \lambda}$ radiometric values. The merit function in Equation (6) was extended with terms containing prior information and the measurement uncertainties as follows:

$$
\begin{aligned}
M_{\text {inv }}\left(N,\left\{C_{i}\right\} i_{1=p}\right) & =\sum_{\lambda}^{n_{\lambda}} \frac{\left(R_{\text {mes }, \lambda}-R_{\text {mod }, \lambda}\left(N,\left\{C_{i}\right\} i_{1=p}\right)\right)^{2}}{\sigma_{R_{m e s}}^{2}}+\sum_{\lambda}^{n_{\lambda}} \frac{\left(T_{m e s, \lambda}-T_{\text {mod }, \lambda}\left(N,\left\{C_{i}\right\} i_{1=p}\right)\right)^{2}}{\sigma_{T_{m e s}}^{2}} \\
& +\sum_{j} \frac{\left(V_{j}-V_{j}^{\text {prior }}\right)^{2}}{\sigma_{V_{j} \text { mes }}^{2}}
\end{aligned}
$$

where $j$ indicates number of simultaneously retrieved variables (i.e., $N, C_{a b}, C_{c a r}, C_{a n t}$, $C_{w}$, and $\left.C_{m}\right), V_{j}$ is the estimated value of the variable $j, V_{j}^{\text {prior }}$ is the prior information value of the variable $j, \sigma_{V_{j m e s}}^{2}$ is the variance of the input variable $j$ indicating the prior knowledge uncertainty, and $\sigma_{R_{m e s}}^{2}$ and $\sigma_{T_{m e s}}^{2}$ are uncertainties of the measured reflectance and transmittance, respectively.

We used destructive wet-laboratory measurements of the leaf biochemical constituents as the prior information $\left(V_{j}^{\text {prior }}\right.$ ) (hereafter referred to as the lab prior-based approach), but we also tested non-destructively measured spectral indices, sensitive to the retrieved biochemical compounds but insensitive to other confounding factors (hereafter referred to 
as spectral indices-based approach), as an alternative substitute to the laboratory analytical measurements.

Table 1 shows mathematical expressions of the optical indices that we decided to use as $V_{j}^{\text {prior }}$ in Equation (7). The indices were selected because (1) they were tested on eucalyptus leaves before or (2) they allowed for an accurate and robust estimation of the leaf biochemical constituents regardless of the biological species. Since the published indices for quantitative assessment of the leaf dry matter content were all based on spectral wavelengths beyond $1600 \mathrm{~nm}$ [61,76-78], we could not apply the spectral indices-based approach to estimate dry matter content.

Table 1. Spectral indices selected from the literature as prior information in Equation (7). More details about the indices and their performance are available in referenced literature.

\begin{tabular}{ccc}
\hline $\begin{array}{c}\text { Input } \\
\text { Parameters }\end{array}$ & Index & Reference \\
\hline$C_{a b}$ & $\left(\mathrm{R}_{850}-\mathrm{R}_{710}\right) /\left(\mathrm{R}_{850}+\mathrm{R}_{710}\right)$ & Datt [56] \\
$C_{c a r}$ & $\left(\mathrm{R}_{860}\right) /\left(\mathrm{R}_{550} \times \mathrm{R}_{708}\right)$ & Datt [58] \\
$C_{a n t}$ & $\mathrm{R}_{\text {green }}-1-\mathrm{R}_{\text {red-egde }}{ }^{-1}$ & Gitelson and Solovchenko [49] \\
$C_{w}$ & $\left(\mathrm{R}_{1062}-\mathrm{R}_{1393}\right) /\left(\mathrm{R}_{1062}+\mathrm{R}_{1393}\right)$ & Féret et al. [60] \\
\hline
\end{tabular}

As $V_{j}^{\text {prior }}$ of the mesophyll structure parameter $\mathrm{N}$, we employed values obtained from the independent three-wavelength Fluspect inversion (Section 2.2.1). The use of outputs originating from destructive analyses makes the lab prior-based approach the most accurate but also unsuitable for operational long-term monitoring of leaf biochemical properties. Here, it serves as reference indicating the theoretically best possible performance of the Fluspect inversion when using Equation (7). Each Fluspect inversion loop, estimating one of the six leaf parameters (i.e., $N, C_{a b}, C_{c a r}, C_{a n t}, C_{w}$, and $C_{m}$ ), was run for a specific spectral subdomain sensitive to the given retrieved parameter. The role of these spectral subdomains is two-fold: (1) to minimise probability of the ill-posed inversion [44], and (2) to increase the estimation accuracy [79]. The spectral subdomains of 700-720 nm were used for $C_{a b}$ and 520-560 $\mathrm{nm}$ for $C_{c a r}$ estimations, as suggested in Spafford et al. [79]. For estimation of $C_{a n t}, C_{w}$, and $C_{m}$, their respective absorption spectral ranges from the SACs database [28-30,35], i.e., 450-685 nm, 850-1600 nm, and 450-1600 nm, were exploited.

Finally, accuracies of the retrievals were evaluated with statistical indicators including: $\mathrm{R}^{2}$ for a linear regression between Fluspect-estimated and reference laboratorymeasured values (in case of $N$, values from multivariate inversions and retrieved with Equation (3), RMSE in physical units of each leaf constituent, and the relative normalised RMSE (NRMSE), calculated as:

$$
\mathrm{NRMSE}=\frac{\mathrm{RMSE}}{\bar{X}}
$$

where $\bar{X}$ is a mean of the variable values measured in the laboratory and for the $N$ parameter, retrieved with Equation (3).

\section{Results}

\subsection{Retrieval of $N$ Parameter and Fluspect Verification}

Results of descriptive statistical analyses demonstrate that the training and testing dataset are generally comparable (Appendix A). The median and mean values of the $N$ parameter for training and testing datasets are nearly identical, even though the range in testing $\mathrm{N}$ values is slightly smaller (Table A1). The level of agreement between the modelsimulated and the laboratory-measured optical properties is illustrated in Figure 3. It shows a mismatch between measured and original Fluspect simulated average optical properties for both training and validation datasets. Fluspect leaf reflectance is overestimated in most wavelengths, except between 600 and $740 \mathrm{~nm}$, whereas its transmittance counterpart is 
underestimated from green to red and overestimated in NIR spectral regions. Finally, the modelled leaf absorptance is slightly overestimated between 600 and $700 \mathrm{~nm}$ and, due to systematic reflectance and transmittance overestimations, underestimated between 750 and $1500 \mathrm{~nm}$.
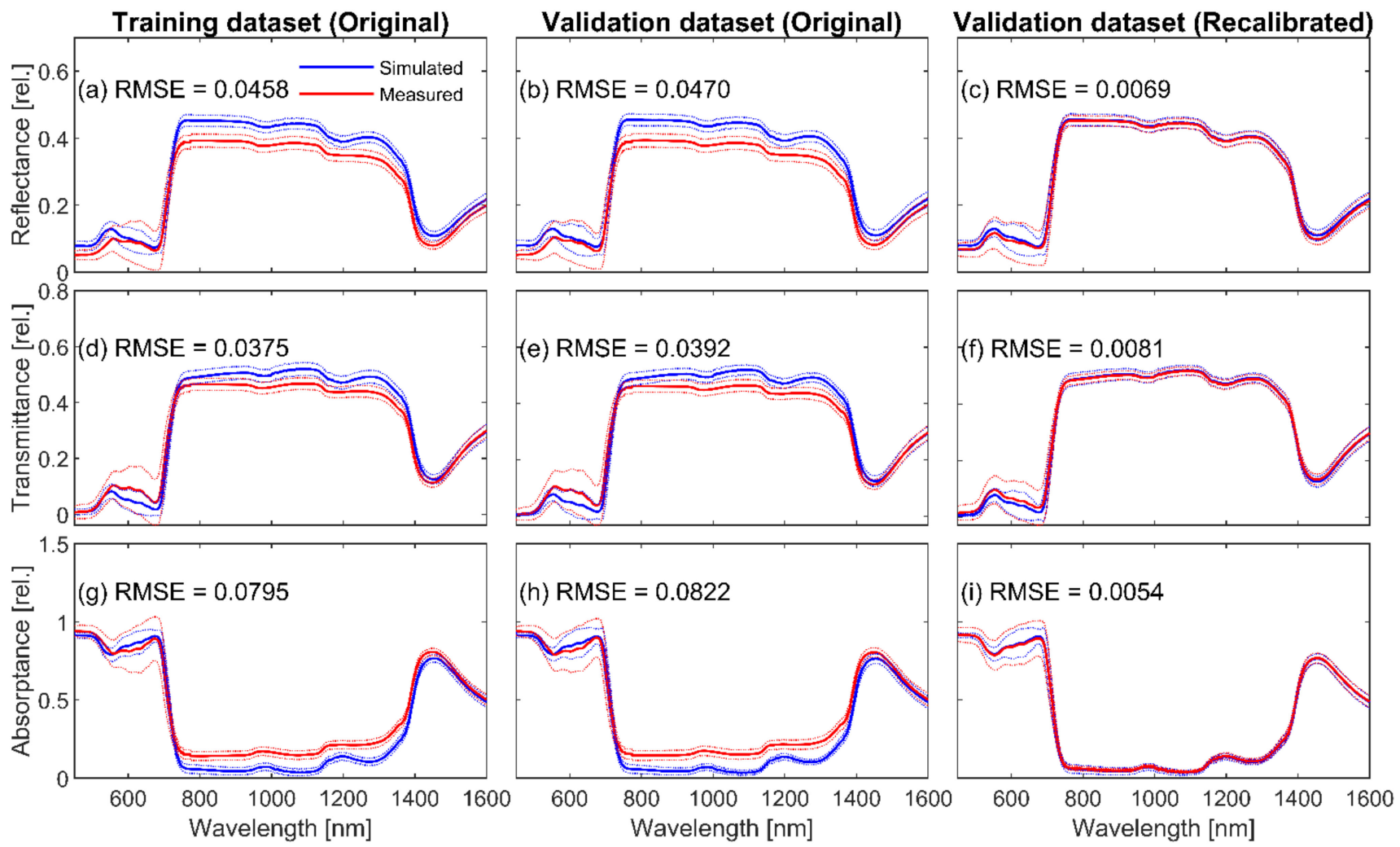

Figure 3. Comparison of the integrating sphere measured and original Fluspect simulated mean optical properties for the training dataset $(\mathbf{a}, \mathbf{d}, \mathbf{g})$ and the validation dataset $(\mathbf{b}, \mathbf{e}, \mathbf{h})$ before and after the model recalibration $(\mathbf{c}, \mathbf{f}, \mathbf{i})$. Solid lines indicate mean optical properties and dashed lines represent $(+/-)$ one standard deviation (RMSE $\sim$ the root mean square error for all investigated wavelengths).

The per-wavelength RMSE (Figure $4 \mathrm{a}, \mathrm{b}, \mathrm{d}, \mathrm{e}, \mathrm{g}, \mathrm{h}$ ) reached up to $6 \%$ in the VIS and up to $8 \%$ in the NIR region for reflectance, up to $10 \%$ in the VIS and close to $6 \%$ in the NIR wavelengths for transmittance, and around $10 \%$ in most spectral regions for absorption. $\mathrm{RMSE}_{\mathrm{s}}$ was higher than RMSE $\mathrm{u}_{\mathrm{u}}$ in most investigated wavelengths, except 551-722 nm for reflectance, $450-500 \mathrm{~nm}$ and $640-690 \mathrm{~nm}$ for transmittance, and 450-750 $\mathrm{nm}$ for absorptance. On the one hand, the results reveal the inability of the original Fluspect to accurately model eucalypt leaf optical properties. On the other hand, similar trends and comparable RMSE values obtained for both datasets indicate their similar representativeness and suggest that the testing data are suitable for Fluspect validation purposes.

\subsection{Calibration of Eucalypt Leaf Refractive Index and Specific Absorption Coefficients}

The leaf refractive index $n(\lambda)$ and SACs of leaf biochemical constituents $k_{\text {spe }}(\lambda)$ for the studied eucalypt species were calibrated through a two-step procedure. The results of $n(\lambda)$ recalibration are shown in Figure 5 and newly obtained SACs are depicted in Figures 6 and 7. The $n(\lambda)$ values retrieved from the training dataset exhibited some unusual spectral artifacts, specifically, a local increase from 450 to $750 \mathrm{~nm}$ (likely due to residual influence of pigment absorbers) and from 1350 to $1600 \mathrm{~nm}$ (region of strong water absorption). Since $n(\lambda)$ is wavelength-dependent and expected to systematically decrease with increasing wavelength [80], the unexpected abrupt changes before 800 and after $1350 \mathrm{~nm}$ were removed and extrapolated using the Matlab function "interp1". Additionally, 
a small local "bump" located at $1000 \mathrm{~nm}$ (i.e., the transitional wavelength between two FieldSpec 3 spectral detectors) was removed and the missing values were linearly interpolated. The corrected eucalypt-specific $n(\lambda)$ values were found to be systematically larger, ranging from 1.38 to 1.57 , than their original values.

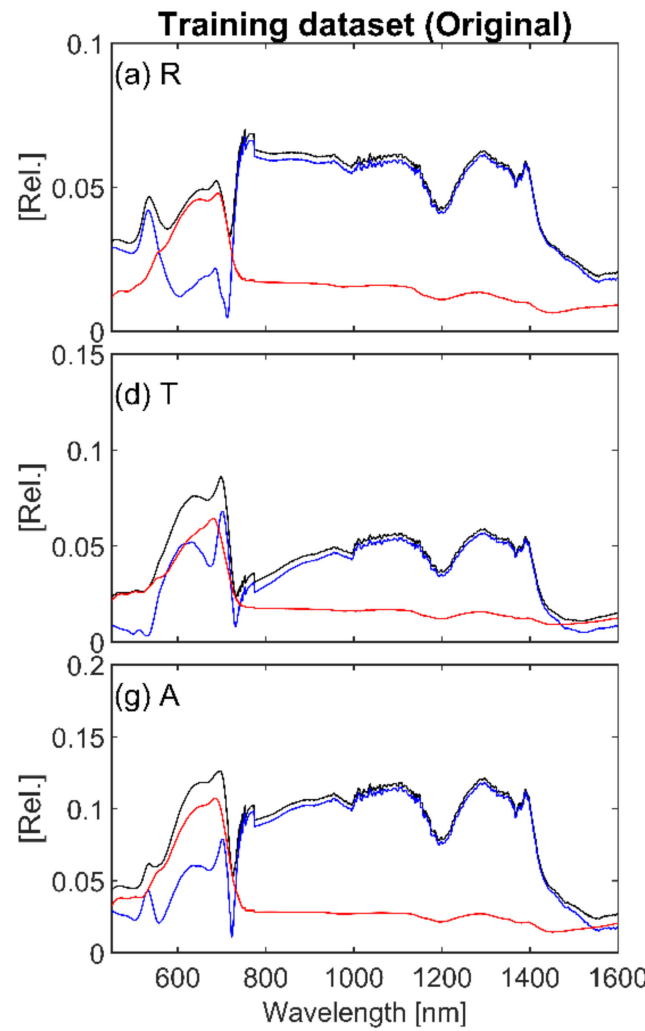

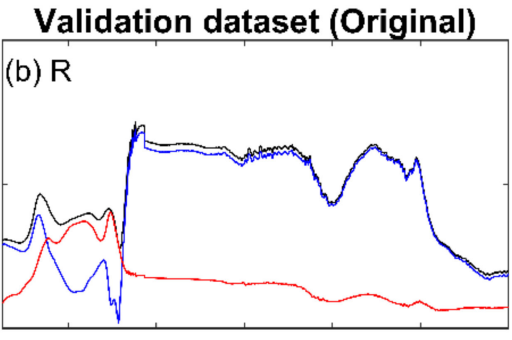
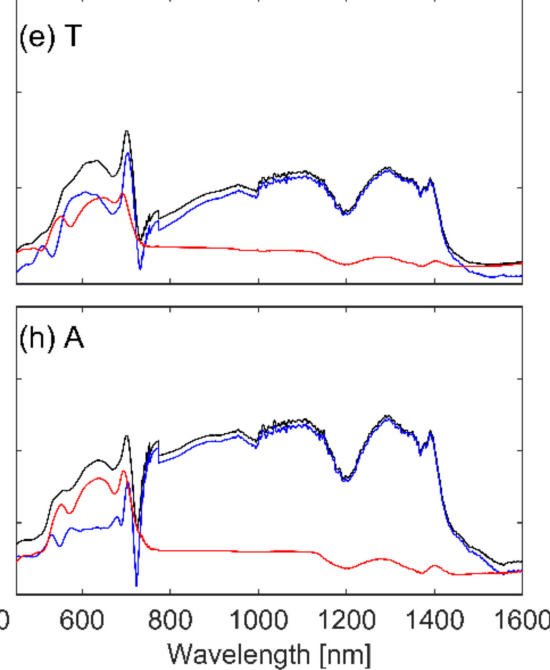

Validation dataset (Recalibrated)
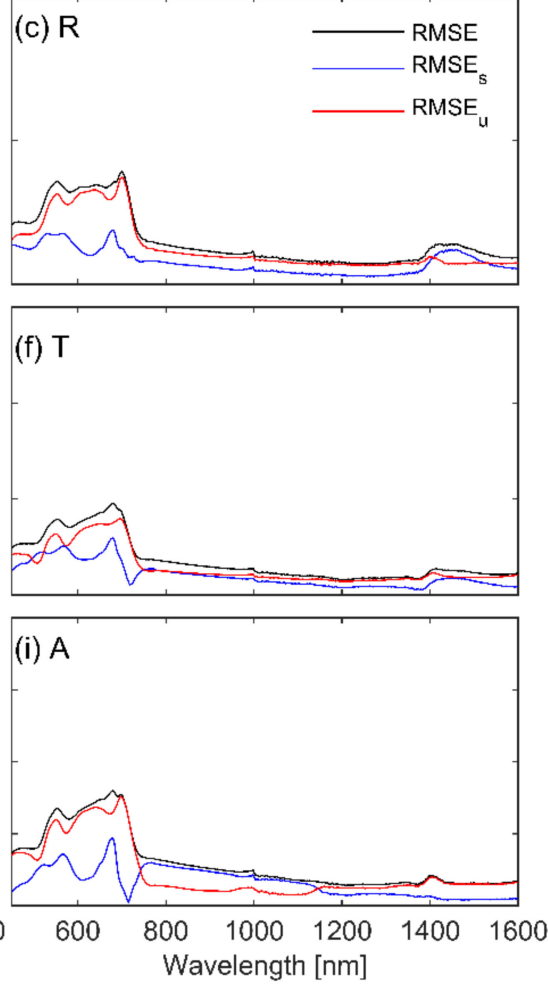

Figure 4. Per-wavelength root mean square errors between measured and modelled reflectance (R), transmittance (T) and absorptance (A) of eucalypt leaf samples in the training $(\mathbf{a}, \mathbf{d}, \mathbf{g})$ and testing $(\mathbf{b}, \mathbf{e}, \mathbf{h})$ datasets simulated with original Fluspect, and testing dataset simulated with recalibrated Fluspect (c,f,i) (RMSE, RMSE $\mathrm{S}_{\mathrm{s}}$ and $\mathrm{RMSE}_{\mathrm{u}} \sim$ total, systematic and unsystematic root mean square errors, respectively). Optimal Fluspect performance is indicated by $\mathrm{RMSE}_{\mathbf{u}}$ close to total RMSE and $\mathrm{RMSE}_{\mathrm{S}}$ close to zero.

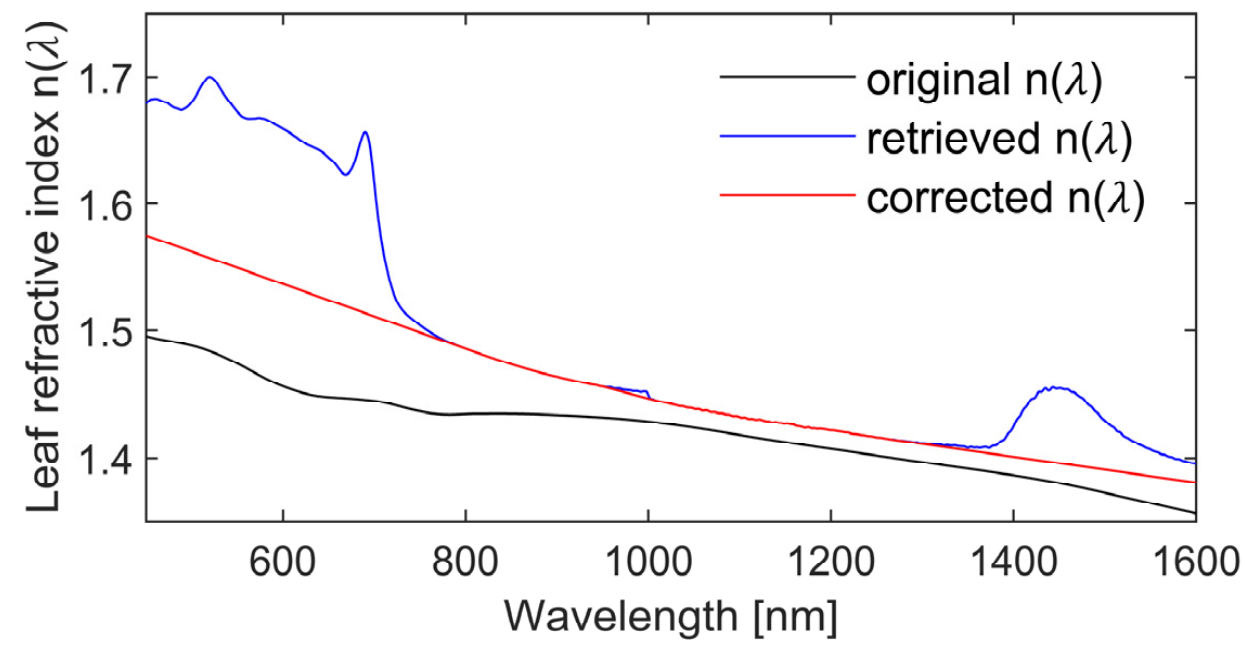

Figure 5. Leaf refractive index computed from simultaneous retrievals with SACs of eucalypt leaf absorbers (blue line), the final corrected index (red line), and the original Fluspect $n(\lambda)$ (black line). 
The eucalypt-specific SACs, retrieved using the corrected $n(\lambda)$ values, revealed that new $k_{a b}$ is lower in the blue spectral domain and slightly higher in red and red-edge domains (Figure 6a). Similarly, lower recalibrated values were observed for $k_{c a r}$ between 450 and $540 \mathrm{~nm}$, reducing the maximum of $k_{c a r}$ from 0.155 to $0.091 \mathrm{~cm}^{2} \cdot \mu \mathrm{g}^{-1}$ (Figure $6 \mathrm{~b}$ ). The re-established $k_{\text {ant }}$ values were comparable to those of the original Fluspect, however, a deviation between 510 and $560 \mathrm{~nm}$ appeared as a double peak with a local minimum centred at $530 \mathrm{~nm}$ (Figure 6c). The recalibrated $k_{w}$ (Figure 7a) is lower than the original one, especially around the absorption peak, centred at $1450 \mathrm{~nm}$. Finally, recalibration changes for $k_{m}$ values were negligible throughout the VIS wavelengths until the red-edge inflection point at $725 \mathrm{~nm}$ (Figure 6d). Beyond this wavelength, $k_{m}$ values systematically dropped by half or even more, before converging towards the original values from $1400 \mathrm{~nm}$ onwards (Figure $7 b$ ).

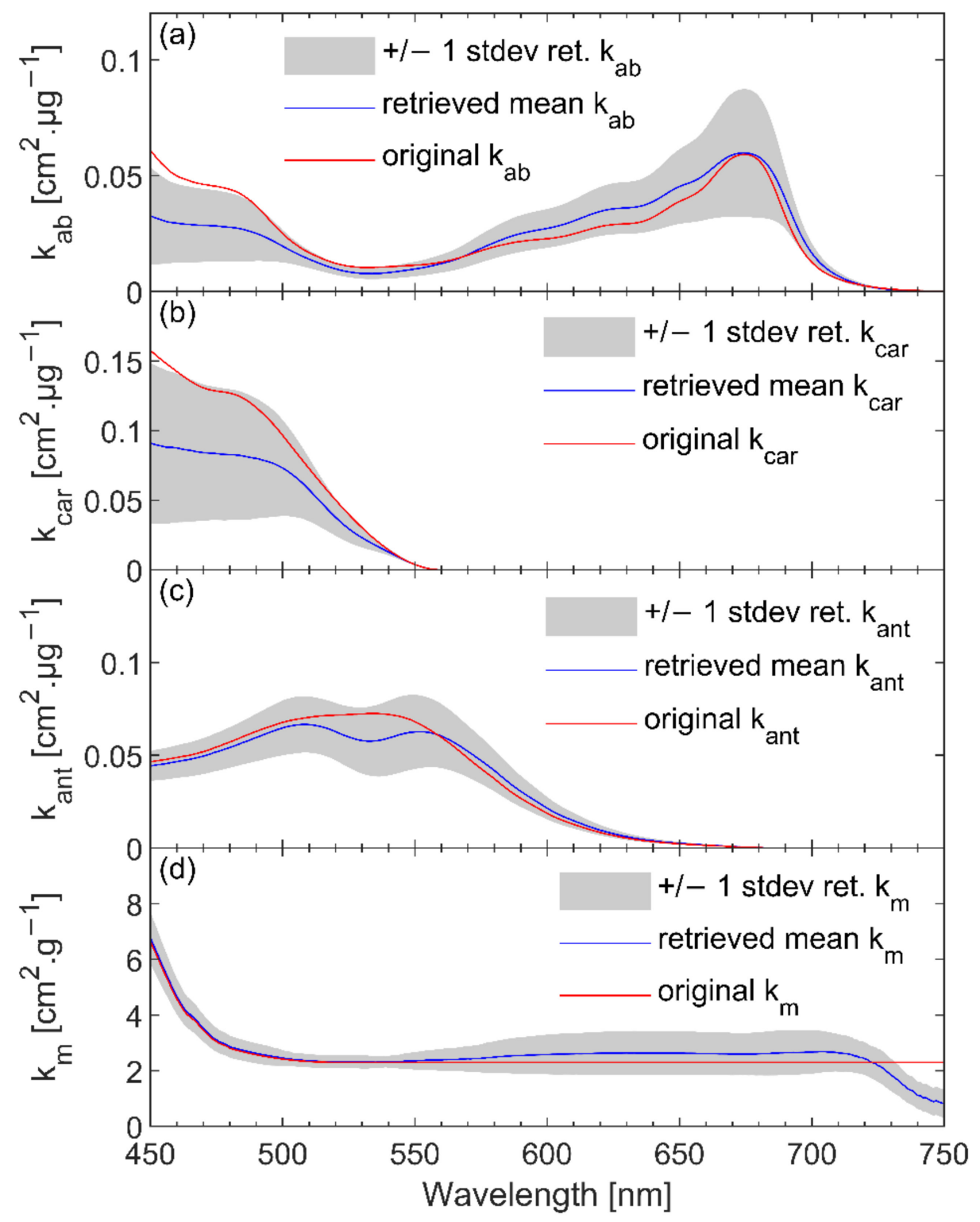

Figure 6. Comparison of newly retrieved and original Fluspect specific absorption coefficients of chlorophyll $a+b\left(k_{a b}\right)(\mathbf{a})$, total carotenoids $\left(k_{c a r}\right)(\mathbf{b})$, anthocyanins $\left(k_{a n t}\right)(\mathbf{c})$ and dry matter $\left(k_{m}\right)$ (d) from 450 to $750 \mathrm{~nm}$. The red lines correspond to SACs in the original Fluspect model, and the blue lines are the newly retrieved eucalypt-specific SACs. The grey area represents the $(+/-)$ one standard deviation of recalibrated SACs. 


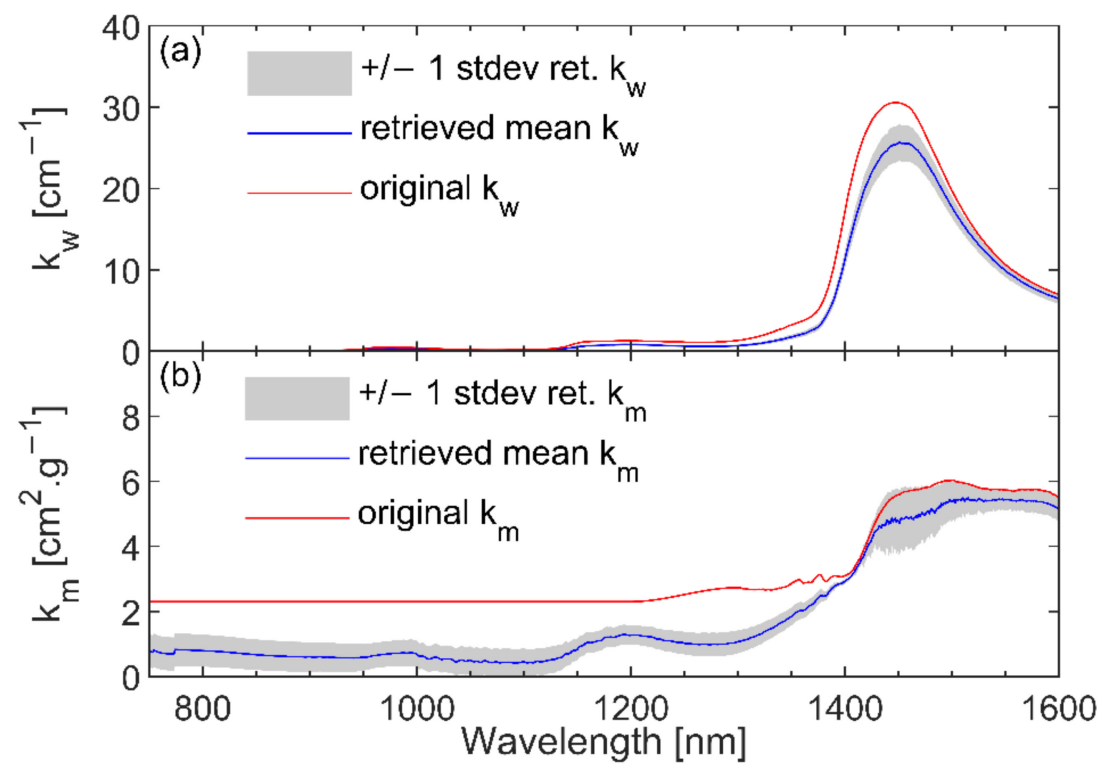

Figure 7. Comparison of newly retrieved and original Fluspect specific absorption coefficients of water $\left(k_{w}\right)(\mathbf{a})$ and dry matter content $\left(k_{m}\right)(\mathbf{b})$ from 750 to $1600 \mathrm{~nm}$. For the legends' explanation see caption of Figure 6.

\subsection{Validation of Recalibrated Fluspect through Forward Modelling}

The first validation of the recalibrated Fluspect was conducted via forward simulations of leaf optical properties using laboratory measured leaf biochemical constituents and $\mathrm{N}$ parameters retrieved with Equation (3) and their comparison with corresponding field optical measurements in the testing dataset. As depicted in Figure $3 \mathrm{c}, \mathrm{f}, \mathrm{i}$, the means and standard deviations of simulated and measured optical properties match quite closely. The average RMSE computed for reflectance, transmittance and absorptance across all wavelengths was $<1 \%\left(R^{2}=0.99\right)$. Some minor differences remained in the VIS region, however, the per-wavelength $\mathrm{RMSE}_{\mathrm{u}}>\mathrm{RMSE}_{\mathrm{s}}$ suggest that they are caused by the quality and errors in the input measurements and not by the model itself. The magnitude of spectral changes in per-wavelength RMSE, $\mathrm{RMSE}_{\mathrm{S}}$ and $\mathrm{RMSE}_{\mathrm{u}}$ are, in general, similar for both reflectance and transmittance (Figure $4 \mathrm{c}, \mathrm{f}, \mathrm{i})$, with RMSE $<4 \%$ in the VIS and $<1 \%$ in the NIR region, respectively. The only case when RMSE $E_{S}$ continuously overestimated $\mathrm{RMSE}_{\mathrm{u}}$ was absorptance between 750 and $1150 \mathrm{~nm}$, with the per-wavelength total RMSE values $<8 \%$.

\subsection{Multivariate Retrieval of Model Inputs with Analytical and Spectral Constraints}

Next, we compared the performance of both the original and recalibrated Fluspect versions using inversions simultaneously retrieving all model inputs from measured leaf optical properties of the testing dataset. The accuracies were evaluated with $\mathrm{R}^{2}$, RMSE, and NRMSE for the following cases: (A) an unconstrained inversion of original Fluspect, (B) an unconstrained inversion of recalibrated Fluspect, $(C)$ an inversion of recalibrated Fluspect constrained by spectral indices, and (D) an inversion of recalibrated Fluspect constrained by laboratory measurements (Table 2 and Figure 8 ).

Results show that case (A) is the least accurate out of all investigated inversions, whereas the new eucalypt specific $n(\lambda)$ and SACs improved the accuracy in case (B). Significantly higher accuracies were found for estimations of $C_{a b}$ and $C_{c a r}$, respectively, and the recalibration corrected the systematic underestimations of $C_{w}$ and mainly $C_{m}$ (c.f. graphs in Figure $8 \mathrm{e}, \mathrm{f}, \mathrm{k}, \mathrm{l})$. The statistical assessment also indicated improved retrieval of the leaf structure parameter $\mathrm{N}$, which is in case (B) the most accurate out of all tested inversions, while the estimation accuracy of $C_{a n t}$ remained unaffected. A slightly improved performance of the recalibrated Fluspect inversion constrained by selected spectral indices, case (C), was found only for estimation of $C_{c a r}$. For the rest of the estimated variables, the accuracy 
remained practically unchanged $\left(C_{a b}\right.$ and $\left.C_{a n t}\right)$ or slightly decreased $\left(\mathrm{N}\right.$ and $\left.C_{w w}\right)$ when compared to case (B). Finally, case (D) produced accuracies that were higher or equal to the previous estimations. A remarkable improvement was achieved for $C_{w}$ and $C_{m}$, but the estimation accuracies for $C_{a b}, C_{c a r}$ and $C_{a n t}$ were only marginally better. Regression between the mesophyll structure parameters obtained from the three-wavelength single-variable retrieval (Equation (3); labelled as "estimated N") and from the multiple-wavelength multivariate retrievals (Equations (6) and (7); labelled as "retrieved N") was slightly weakened, as no prior information concerning $\mathrm{N}$ was available and, consequently, could not be implemented in any of the retrieval equations. Nevertheless, the RMSE and NRMSE values for $\mathrm{N}$ were consistently small.

Table 2. Root mean square error (RMSE) and its normalised form (NRMSE) computed between measured and estimated Fluspect inputs obtained through four retrieval approaches (A, B, C, and D) applied to the testing dataset as described in caption of Figure 8. The lowest achieved error values are highlighted in bold fonts.

\begin{tabular}{|c|c|c|c|c|c|c|c|c|}
\hline \multirow{2}{*}{$\begin{array}{c}\text { Retrieved } \\
\text { Model Inputs }\end{array}$} & \multicolumn{4}{|c|}{ RMSE } & \multicolumn{4}{|c|}{ NRMSE (Relative) } \\
\hline & A & B & $\mathrm{C}$ & D & $\mathbf{A}$ & B & $\mathrm{C}$ & D \\
\hline$N$ & 0.0695 & 0.0234 & 0.0698 & 0.0259 & 0.0506 & 0.0170 & 0.0509 & 0.0189 \\
\hline$C_{a b}\left(\mu \mathrm{g} \cdot \mathrm{cm}^{-2}\right)$ & 14.0227 & 9.3314 & 10.3809 & 8.4600 & 0.4099 & 0.2727 & 0.3034 & 0.2473 \\
\hline$C_{c a r}\left(\mu \mathrm{g} \cdot \mathrm{cm}^{-2}\right)$ & 7.7003 & 4.2890 & 3.5997 & 3.8261 & 0.6203 & 0.3455 & 0.2900 & 0.3082 \\
\hline$C_{a n t}\left(\mu \mathrm{g} \cdot \mathrm{cm}^{-2}\right)$ & 1.7144 & 1.7007 & 1.8294 & 1.6920 & 0.3761 & 0.3731 & 0.4013 & 0.3712 \\
\hline$C_{w}(\mathrm{~cm})$ & 0.0032 & 0.0024 & 0.0050 & 0.0013 & 0.1510 & 0.1123 & 0.2350 & 0.0655 \\
\hline$C_{m}\left(\mathrm{~g} \cdot \mathrm{cm}^{-2}\right)$ & 0.0098 & 0.0061 & NA & 0.0036 & 0.5704 & 0.3587 & NA & 0.2128 \\
\hline
\end{tabular}
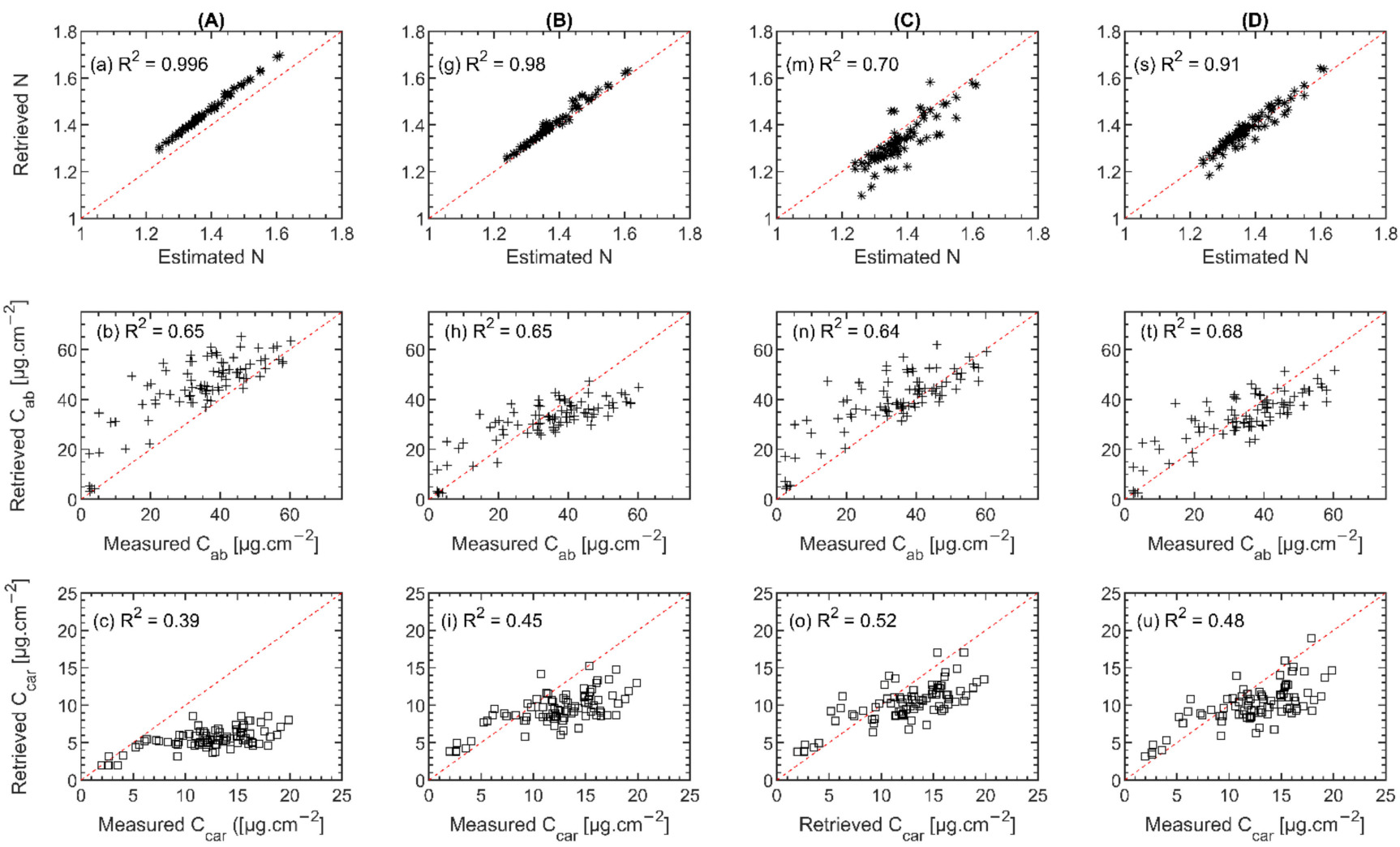

Figure 8. Cont. 

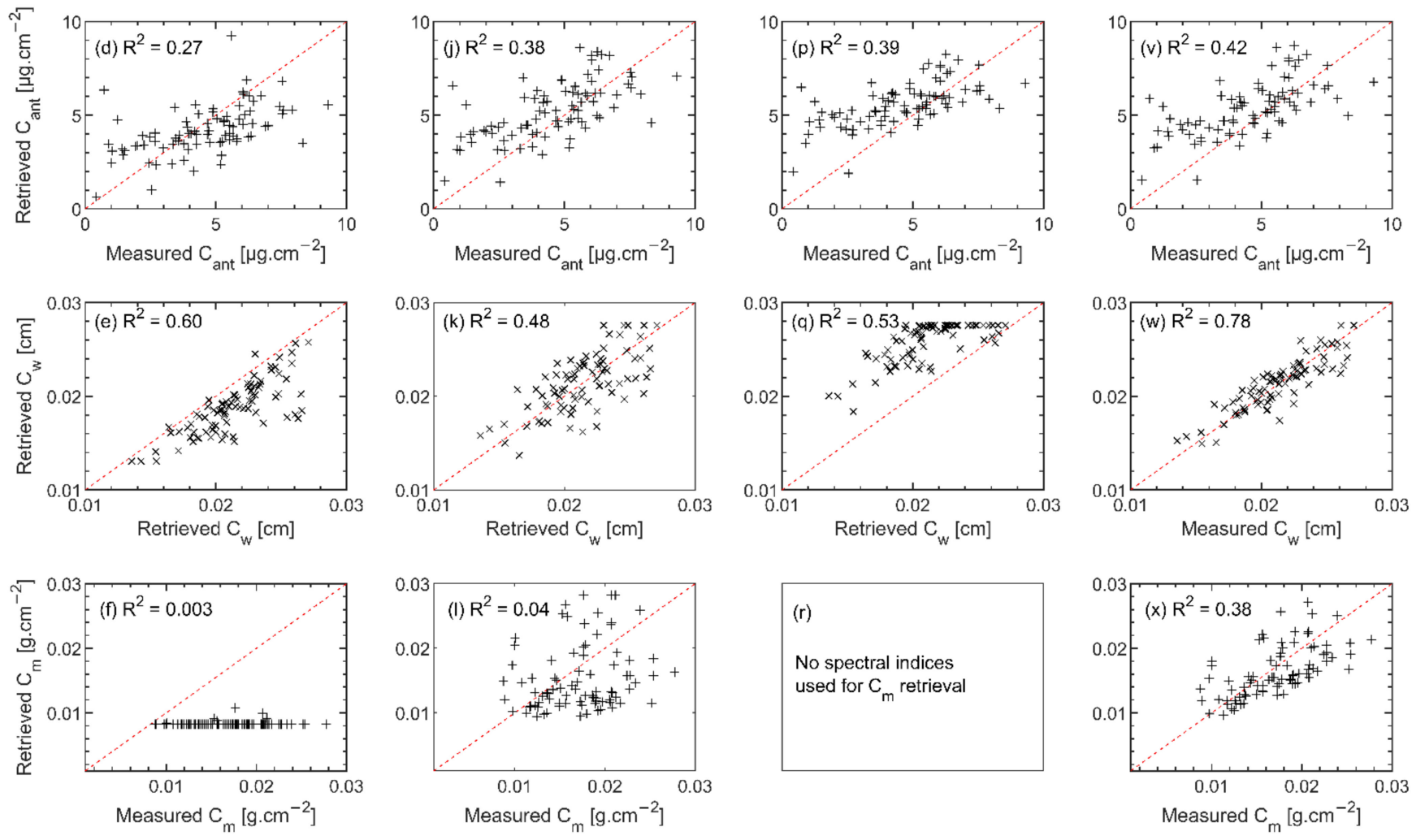

Figure 8. Results of the unconstrained inversion of original Fluspect-case (A), the unconstrained inversion of recalibrated Fluspect-case (B), inversion of recalibrated Fluspect constrained by selected spectral indices-case (C), and inversion of recalibrated Fluspect constrained by laboratory measurements of the retrieved variables—case (D), retrieving simultaneously all the model inputs $(N$, $C_{a b}, C_{c a r}, C_{a n t}, C_{w}$ and $C_{m}$ ) from optical properties of 85 leaf samples stored in the testing (validation) dataset. "Estimated N" is the mesophyll structure parameter obtained from the three-wavelength single-variable retrieval, while "retrieved N" was obtained from the multivariate retrievals. $\mathrm{R}^{2}$ is coefficient of determination of a linear regression established between retrieved and measured values; red dashed line represents the one-to-one relationship between measured and retrieved values.

\section{Discussion}

\subsection{Fluspect Verification and Recalibration}

This study developed a species-specific version of the Fluspect radiative transfer model for accurate retrievals of leaf biochemical traits of two temperate eucalypt species. To assess the Fluspect performance, we had to determine the leaf mesophyll structure parameter $N$ of 284 leaf samples. Eucalypt $N$ values, ranging between 1.17 and 1.70, are lower than the previously retrieved values for dicotyledon leaves, ranging from 1.5 to 2.5 [27]. This can be explained by an isobilateral morphology of eucalypt leaves, formed by optically thin multiple palisade cells beneath epidermal layers, interrupted by numerous oil glands [69]. The retrieved $N$ values and corresponding contents of biochemical constituents were used to determine if Fluspect accurately simulated leaf directional-hemispherical reflectance and transmittance from 450 to $1600 \mathrm{~nm}$ for the same measured eucalypt leaves. The spectral fit between measured and Fluspect-simulated optical properties was poor because of unsuitable refractive index $n(\lambda)$ and SACs stored in the original Fluspect database of optical parameters.

To achieve general applicability, leaf radiative transfer models are calibrated with measurements acquired from a wide range of biological species. However, this generic calibration limits their accuracy in cases of anatomically and biochemically unique leaves such as eucalypt foliage. In these cases, Fluspect may require a recalibration of internal optical constants (i.e., leaf refractive index $n(\lambda)$ and the SACs of the leaf absorbers) using 
species-specific field data and laboratory measurements. On one hand, the new calibration causes the model to lose its universality but, on the other hand, increases its accuracy for these specific biological species. In principle, our recalibrated Fluspect should be applicable to any species of the Eucalyptus genus, under the condition that their leaf structural, biochemical and resulting optical properties are comparable with those of the two species employed in this study.

The newly calibrated eucalypt-specific $n(\lambda)$ values are higher than those used in the original Fluspect [35] and also in previous versions of the PROSPECT model [28,29]. Two unusual spectral features of $n(\lambda)$ in the VIS and SWIR wavelengths were residual artifacts of strong foliar pigment and water absorptions [29]. As they were not observed in $n(\lambda)$ values estimated using an albino leaf by [27], we removed them and extrapolated the missing $n(\lambda)$ values.

SACs of leaf constituents were recalibrated from optical properties within optimal spectral subdomains, i.e., wavelength ranges where given constituents are absorbed. The in vivo recalibration of SACs through an inversion of leaf optical properties is a challenging task, especially in the NIR domain, where leaves exhibit a generally low absorption causing possibly considerable uncertainty in their measured optical properties [30]. An accurate determination and separation of SACs is also complicated by overlapping absorption features of different biochemical compounds, especially pigments $C_{a b}, C_{c a r}$ and $C_{a n t}$ in the visible region (see Figure A1), and high correlations between the contents of leaf constituents. The recalibrated $k_{a b}$ beyond $500 \mathrm{~nm}$ were in good agreement with the original values. However, noticeable differences were observed in $k_{a b}$ and mainly $k_{c a r}$ between 450 and $500 \mathrm{~nm}$, which may be caused by the increased presence and absorption effects of flavonoid pigments [29]. This hypothesis could not be verified because the content of flavonoids inside the investigated eucalypt leaves was not measured. Moreover, the flavonoid analysis using HPLC is less reliable as compared to other foliar pigments.

Recalibrated $k_{\text {ant }}$ created a double-peak shape with two local maxima at around 510 and $560 \mathrm{~nm}$. This is in agreement with the absorption spectra of cyanidin-3-glucoside (C3G) (Fossen et al. [81]), which is one of the most common anthocyanins present in eucalypt leaves [82]. This effect is overlying with the spectral wavelengths for predicting the xanthophyll epoxidation state, analysed for the same species with a partial least squares regression approach by Woodgate et al. [83]. The impacts of leaf age, phenological state, lighting environment, and short- and long-term stressors warrant further research for the spectral link with epoxidation state.

Recalibrated $k_{w}$ and $k_{m}$ values in the SWIR region are systematically lower than in the original Fluspect. The $k_{m}$ differences can be attributed to differences in the composition of dry matter in eucalypt leaves combined with residual impacts originating from a strong water absorption taking place in longer wavelengths.

The model recalibration and verification uncertainties do not originate only from the applied model inversion procedure but are additionally associated with the model inputs and measurement protocols used for field sampling [32]. For instance, measurement of a foliar pigment content involves a series of steps, including a collection of leaf disks in the field, deep freezing, transportation and storage, pigment extraction in a liquid solvent, spectrophotometric measurement, etc., which may result in degradation or modification of sampled material and consequently produce erroneous results [84]. Féret et al. [30] found that the presence of brown pigments, if not being accounted for during the model recalibration, may result in a higher RMSE in leaf optical properties of shorter wavelengths. We did not account for brown pigments in our recalibration process as they were not present in our samples.

Another factor influencing the quality of the optical measurements is the technical limits of the instrumentation. For example, potential power instability of the light source or a lower quality of a white standard used for referencing optical measurements may generate random or systematic noise in leaf optical properties. Despite these potential confounding factors, our recalibrated SACs improved the model performance, which was confirmed 
with lower per-wavelength RMSEs once we compared Fluspect forward simulations with corresponding in situ measurements (Figure 4c,f,i).

\subsection{Fluspect Multivariate Inversions}

Multivariate model inversions showed that Fluspect recalibrated for the two eucalypt species provided more accurate predictions of the input parameters than its original version. Fluspect inversion with lab-based prior information yielded the lowest RMSE of $8.46 \mu \mathrm{g} \cdot \mathrm{cm}^{-2}$ for $C_{a b}$ estimation, which is between $9.00 \mu \mathrm{g} \cdot \mathrm{cm}^{-2}$ obtained for multiple species from a PROSPECT inversion by Féret et al. [29] and $7.88 \mu \mathrm{g} \cdot \mathrm{cm}^{-2}$ obtained for eucalypts by Barry and Newnham [42] with PROSPECT-5. On the other hand, it is less accurate than the RMSE of $5.00 \mu \mathrm{g} \cdot \mathrm{cm}^{-2}$ obtained from a PROSPECT inversion of eucalypt leaf optical properties by Barry et al. [41].

The lowest achieved $C_{\text {car }}$ RMSE of $3.60 \mu \mathrm{g} \cdot \mathrm{cm}^{-2}$ is better than $5.39 \mu \mathrm{g} \cdot \mathrm{cm}^{-2}$ obtained by Barry and Newnham [42] with PROSPECT-5 for Eucalyptus nitens and Eucalyptus globulus leaves. Similar recalibration improvements are observed for $C_{a n t}$ estimation, with the lowest $C_{\text {ant }}$ RMSE of $1.69 \mu \mathrm{g} \cdot \mathrm{cm}^{-2}$ being comparable to $1.79 \mu \mathrm{g} \cdot \mathrm{cm}^{-2}$ obtained by Féret et al. [28] when inverting PROSPECT-D.

Estimations of $C_{w}$ and $C_{m}$ turned out to be most accurate when using laboratorybased prior information. Our retrieval of $C_{m}$ yielded a relatively less accurate result $\left(\mathrm{RMSE}=0.0036 \mathrm{~g} \cdot \mathrm{cm}^{-2}\right.$ ) than published by Romero et al. [77] and Ali et al. [45], achieving RMSEs of around $0.0015 \mathrm{~g} \cdot \mathrm{cm}^{-2}$ and $0.0018 \mathrm{~g} \cdot \mathrm{cm}^{-2}$, respectively. However, our accuracy of $C_{w}$ estimates (RMSE $=0.0013 \mathrm{~cm}$ ) is higher than the estimates for broadleaf samples $(\mathrm{RMSE}=0.0019 \mathrm{~cm})$ obtained by Ali et al. [45]. Yet, the shortcoming that water and dry matter absorptions occurring beyond $1600 \mathrm{~nm}$ could not be considered due to equipment limitations is a handicap that should be remediated in upcoming studies.

Prediction errors of this study may be partly attributed to the presence of epicuticular waxes. This hypothesis is consistent with the conclusions of Holmes and Keiller [85], who found that wax on top of eucalypt leaves has a noticeable effect on leaf reflectance, especially at photosynthetic wavelengths. Barry and Newnham [42] pointed out that the presence of cuticular waxes led to an incorrect assessment of pigments, especially carotenoids, in Eucalyptus globulus and Eucalyptus nitens leaves. Since the wax content varies according to the leaf age [41], the reflectance may differ significantly for waxy and wax-less eucalypt leaf surfaces [85]. This impact should be further investigated.

\subsection{Limiting the Fluspect Ill-Posed Inversion}

To minimise the occurrence of ill-posed Fluspect inversion, we tested a new multivariate retrieval approach constrained by reflectance-based spectral indices sensitive to the retrieved leaf biochemical constituents. Our results, especially a high accuracy obtained for $C_{c a r}$ estimations, suggest that the use of optical indices could be a promising alternative to destructive laboratory measurements. Despite this, the spectral indices computed from the sample-specific reflectance are still subject to measurement errors that subsequently propagate into estimations of leaf traits. Further research should investigate the sensitivity of the indices to various types of noise and measurement errors. Overall, the laboratory measurements were, as expected, still the best prior knowledge, even with associated uncertainties and potential errors originating from leaf sample processing and measurements [86].

\section{Conclusions}

We assessed the applicability of the Fluspect-Cx model to simulate hemisphericaldirectional reflectance and transmittance between 450 and $1600 \mathrm{~nm}$ and to estimate leaf biochemical traits of two Australian eucalypt species. A comparison between the model simulated and measured leaf optical properties revealed the poor performance of the original Fluspect calibration. Hence, we recalibrated the leaf refractive index and in vivo SACs using leaf optical properties of the eucalypt species. This allowed Fluspect to simulate 
relative spectral properties of mountain gum and alpine ash leaves with a mean RMSE smaller than $1 \%$.

The recalibration also improved the model inversion performance. The highest accuracy was achieved with a constrained nonlinear optimisation incorporating laboratory measurements as prior knowledge and uncertainties associated with radiometric and laboratory measurements. The noticeable achievement of this study was an improvement of carotenoid and anthocyanin estimations' accuracies. We investigated the possibility of substituting leaf biochemical prior information with non-invasive vegetation spectral indices sensitive to the biochemical traits of interest. The high total carotenoid retrieval accuracy suggests that spectral indices may be a promising alternative to time-consuming and labour-intensive laboratory measurements. However, future studies investigating different types of spectral indices and their sensitivity to the spectral measurement quality are recommended. Further, future investigations could also test the performance of the newly recalibrated model for other eucalypt species.

This study paves the way for future research developing quantitative remote sensing stress mapping methods for Australian eucalypt forests using imaging spectroscopy data and radiative transfer modelling. The obtained results suggest that coupling Fluspect with a canopy radiative transfer model may provide an efficient tool to retrieve quantitative leaf morphological and biochemical characteristics indicating early onset stress symptoms. Such thematic maps will be highly relevant for timely and targeted forest management.

Author Contributions: Conceptualisation, K.L. and Z.M.; Formal analysis, K.L.; Funding acquisition, Z.M. and W.W.; Investigation, K.L., Z.M., W.W. and M.W.; Methodology, K.L., Z.M. and M.W.; Supervision, Z.M., T.J.B. and J.A.; Writing—original draft, K.L.; Writing-review and editing, K.L., Z.M., W.W., M.W., T.J.B. and J.A. All authors have read and agreed to the published version of the manuscript.

Funding: The study was carried out within the Australian Research Council Future Fellowship of Zbyněk Malenovský (FT160100477) "Bridging scales in remote sensing of vegetation stress". William Woodgate is supported by an Australian Research Council DECRA Fellowship (DE190101182). The OzFlux and SuperSite Network is supported by the National Collaborative Infrastructure Strategy (NCRIS) through the Terrestrial Ecosystem Research Network (TERN).

Data Availability Statement: Data available on request.

Acknowledgments: We thank Arko Lucieer (University of Tasmania) for his critical reading of the draft manuscript. We acknowledge Mark Kitchen, Anthony Nadelko and Juergen Knauer (CSIRO) and Shukhrat Shokirov (Australian National University) for their support of our field work. We acknowledge the use of high-performance computing facilities provided by the Tasmanian Partnership for Advanced Computing (TPAC). TPAC is funded and hosted by the University of Tasmania.

Conflicts of Interest: The authors declare no conflict of interest.

\section{Appendix A. Descriptive Statistical Analysis of Fluspect Training and Testing Datasets}

Results of descriptive statistics for training and testing datasets are presented in Table A1. The statistical results for Fluspect inputs of both datasets are consistent, even though the training dataset contains more samples with a low $C_{a b}$ than the testing dataset. 
Table A1. Descriptive statistics of laboratory-measured Fluspect input parameters for training and testing datasets used in this study. The values of the leaf structure parameter $\mathrm{N}$ were retrieved from optical properties of the training and testing dataset by Fluspect inversion (see Section 2.2.1). Abbreviations of leaf constituents' contents: $C_{a b} \sim$ chlorophyll $a+b, C_{c a r} \sim$ total carotenoids, $C_{a n t} \sim$ anthocyanins, $C_{w} \sim$ water and $C_{m} \sim$ dry matter; " $n$ " $=$ the total number of samples in the dataset.

\begin{tabular}{|c|c|c|c|c|c|c|}
\hline Count & Minimum & Maximum & Range & Median & Mean & Std. Dev. \\
\hline \multicolumn{7}{|c|}{ Training (Calibration) Dataset $(n=199)$} \\
\hline$N$ & 1.17 & 1.70 & 0.52 & 1.35 & 1.36 & 0.08 \\
\hline$C_{a b}\left(\mu \mathrm{g} \cdot \mathrm{cm}^{-2}\right)$ & 0.56 & 67.59 & 67.02 & 37.44 & 34.46 & 14.97 \\
\hline$C_{c a r}\left(\mu \mathrm{g} \cdot \mathrm{cm}^{-2}\right)$ & 0.45 & 21.53 & 21.08 & 12.66 & 12.34 & 3.98 \\
\hline$C_{\text {ant }}\left(\mu \mathrm{g} \cdot \mathrm{cm}^{-2}\right)$ & 0.02 & 9.19 & 9.17 & 4.73 & 4.66 & 1.74 \\
\hline$C_{w}(\mathrm{~cm})$ & 0.0144 & 0.0303 & 0.0159 & 0.0214 & 0.0217 & 0.0025 \\
\hline$C_{m}\left(\mathrm{~g} \cdot \mathrm{cm}^{-2}\right)$ & 0.0084 & 0.0254 & 0.0170 & 0.0162 & 0.0167 & 0.0039 \\
\hline \multicolumn{7}{|c|}{ Testing (Validation) Dataset $(n=85)$} \\
\hline$N$ & 1.24 & 1.61 & 0.37 & 1.36 & 1.37 & 0.08 \\
\hline$C_{a b}\left(\mu \mathrm{g} \cdot \mathrm{cm}^{-2}\right)$ & 2.44 & 60.30 & 57.86 & 36.36 & 34.21 & 14.58 \\
\hline$C_{c a r}\left(\mu \mathrm{g} \cdot \mathrm{cm}^{-2}\right)$ & 1.97 & 19.87 & 17.90 & 12.87 & 12.41 & 4.10 \\
\hline$C_{\text {ant }}\left(\mu \mathrm{g} \cdot \mathrm{cm}^{-2}\right)$ & 0.43 & 9.29 & 8.86 & 4.76 & 4.56 & 1.95 \\
\hline$C_{w}(\mathrm{~cm})$ & 0.0136 & 0.0271 & 0.0135 & 0.0213 & 0.0214 & 0.0030 \\
\hline$C_{m}\left(\mathrm{~g} \cdot \mathrm{cm}^{-2}\right)$ & 0.0087 & 0.0277 & 0.0190 & 0.0174 & 0.0171 & 0.0043 \\
\hline
\end{tabular}

The Spearman correlation coefficients, computed among the constituents of both training and testing datasets (Figure A1), were found to be generally consistent, which indicates that the training and testing selections are comparable. As expected, the coefficients indicate strong correlations among foliar pigments. The $C_{m}$ content was found to be moderately positively correlated with leaf pigments $C_{a b}, C_{c a r}$ and $C_{a n t}$, whereas leaf structure parameters $N$ and $C_{w}$ were found to be poorly correlated with the other leaf constituents.
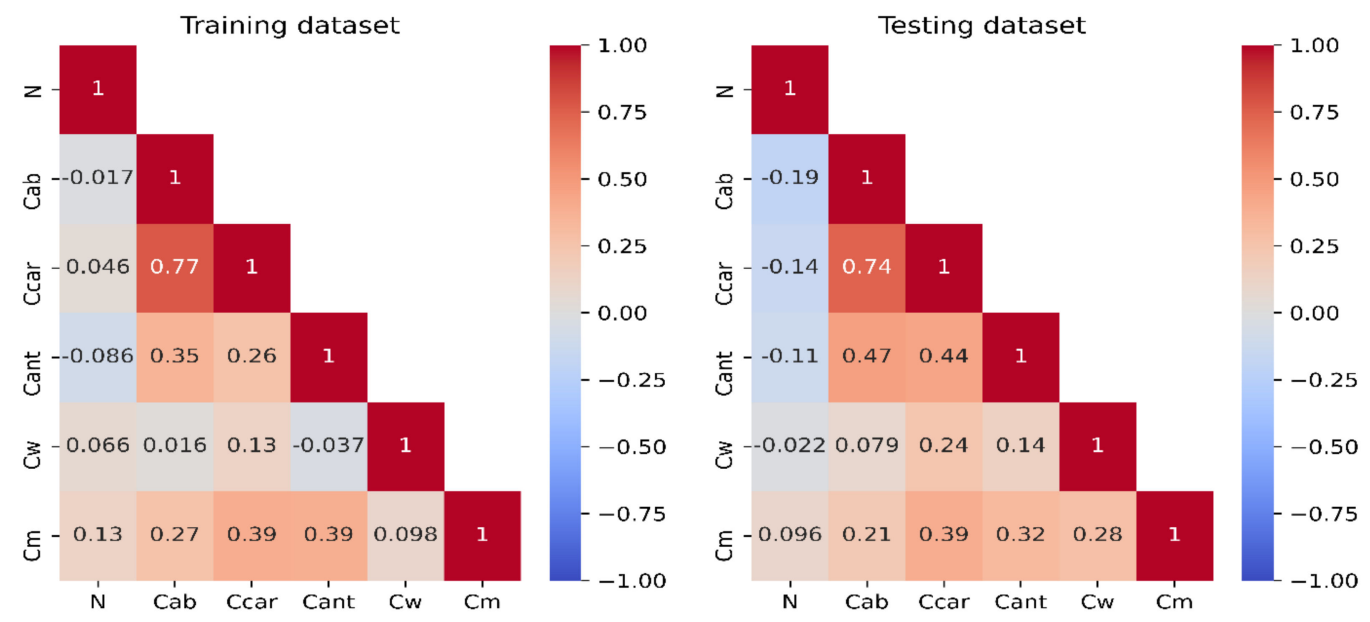

Figure A1. Matrices depicting Spearman's correlation coefficients for Fluspect inputs of training and testing datasets. Negative correlation coefficient values indicate negative relationships of tested variables and vice versa. For abbreviations see caption of Table A1.

\section{References}

1. Kattge, J.; DÍAz, S.; Lavorel, S.; Prentice, I.C.; Leadley, P.; BÖNisch, G.; Garnier, E.; Westoby, M.; Reich, P.B.; Wright, I.J.; et al. TRY-A global database of plant traits. Glob. Chang. Biol. 2011, 17, 2905-2935. [CrossRef]

2. Wright, I.J.; Reich, P.B.; Westoby, M.; Ackerly, D.D.; Baruch, Z.; Bongers, F.; Cavender-Bares, J.; Chapin, T.; Cornelissen, J.H.C.; Diemer, M.; et al. The worldwide leaf economics spectrum. Nature 2004, 428, 821-827. [CrossRef] [PubMed] 
3. Niinemets, Ü. Photosynthesis and resource distribution through plant canopies. Plant Cell Environ. 2007, 30, 1052-1071. [CrossRef] [PubMed]

4. Demmig-Adams, B.; Adams, W.W. Photoprotection in an ecological context: The remarkable complexity of thermal energy dissipation. New Phytol. 2006, 172, 11-21. [CrossRef]

5. Scheiter, S.; Langan, L.; Higgins, S.I. Next-generation dynamic global vegetation models: Learning from community ecology. New Phytol. 2013, 198, 957-969. [CrossRef]

6. Schimel, D.; Pavlick, R.; Fisher, J.B.; Asner, G.P.; Saatchi, S.; Townsend, P.; Miller, C.; Frankenberg, C.; Hibbard, K.; Cox, P. Observing terrestrial ecosystems and the carbon cycle from space. Glob. Chang. Biol. 2015, 21, 1762-1776. [CrossRef]

7. Lichtenthaler, H.K. The stress concept in plants: An introduction. Ann. N. Y. Acad. Sci. 1998, 851, 187-198. [CrossRef]

8. Sharma, A.; Kumar, V.; Shahzad, B.; Ramakrishnan, M.; Singh Sidhu, G.P.; Bali, A.S.; Handa, N.; Kapoor, D.; Yadav, P.; Khanna, K.; et al. Photosynthetic Response of Plants under Different Abiotic Stresses: A Review. J. Plant Growth Regul. 2020, 39, 509-531. [CrossRef]

9. Stone, C.; Coops, N.; Culvenor, D. Conceptual Development of a Eucalypt Canopy Condition Index Using High Resolution Spatial and Spectral Remote Sensing Imagery. J. Sustain. For. 2000, 11, 23-45. [CrossRef]

10. Close, D.C.; Davies, N.W.; Beadle, C.L. Temporal variation of tannins (galloylglucoses), flavonols and anthocyanins in leaves of Eucalyptus nitens seedlings: Implications for light attenuation and antioxidant activities. Funct. Plant Biol. 2001, 28, 269-278. [CrossRef]

11. El-Khatib, A.A.; Youssef, N.A.; Barakat, N.A.; Samir, N.A. Responses of Eucalyptus globulus and Ficus nitida to different potential of heavy metal air pollution. Int. J. Phytoremed. 2020, 22, 986-999. [CrossRef] [PubMed]

12. Barry, K.M.; Stone, C.; Mohammed, C.L. Crown-scale evaluation of spectral indices for defoliated and discoloured eucalypts. Int J. Remote Sens. 2008, 29, 47-69. [CrossRef]

13. Vollenweider, P.; Menard, T.; Arend, M.; Kuster, T.M.; Günthardt-Goerg, M.S. Structural changes associated with drought stress symptoms in foliage of Central European oaks. Trees 2016, 30, 883-900. [CrossRef]

14. Zhang, F.-J.; Zhang, K.-K.; Du, C.-Z.; Li, J.; Xing, Y.-X.; Yang, L.-T.; Li, Y.-R. Effect of Drought Stress on Anatomical Structure and Chloroplast Ultrastructure in Leaves of Sugarcane. Sugar Tech. 2015, 17, 41-48. [CrossRef]

15. Baret, F.; Houles, V.; Guerif, M. Quantification of plant stress using remote sensing observations and crop models: The case of nitrogen management. J. Exp. Bot. 2007, 58, 869-880. [CrossRef] [PubMed]

16. Thomson, V.P.; Nicotra, A.B.; Steinbauer, M.J. Influence of previous frost damage on tree growth and insect herbivory of Eucalyptus globulus globulus. Austral Ecol. 2001, 26, 489-499. [CrossRef]

17. Stone, C.; Chisholm, L.; McDonald, S. Effects of leaf age and psyllid damage on the spectral reflectance properties of Eucalyptus saligna foliage. Aust. J. Bot. 2005, 53, 45-54. [CrossRef]

18. Stone, C.; Coops, N.C. Assessment and monitoring of damage from insects in Australian eucalypt forests and commercial plantations. Aust. J. Entomol. 2004, 43, 283-292. [CrossRef]

19. Asner, G.P.; Martin, R.E.; Knapp, D.E.; Tupayachi, R.; Anderson, C.B.; Sinca, F.; Vaughn, N.R.; Llactayo, W. Airborne laser-guided imaging spectroscopy to map forest trait diversity and guide conservation. Science 2017, 355, 385. [CrossRef]

20. Gamon, J.A.; Somers, B.; Malenovský, Z.; Middleton, E.M.; Rascher, U.; Schaepman, M.E. Assessing Vegetation Function with Imaging Spectroscopy. Surv. Geophys. 2019, 40, 489-513. [CrossRef]

21. Pottier, J.; Malenovský, Z.; Psomas, A.; Homolová, L.; Schaepman, M.E.; Choler, P.; Thuiller, W.; Guisan, A.; Zimmermann, N.E. Modelling plant species distribution in alpine grasslands using airborne imaging spectroscopy. Biol. Lett. 2014, 10, 20140347. [CrossRef] [PubMed]

22. Skidmore, A.K.; Pettorelli, N.; Coops, N.C.; Geller, G.N.; Hansen, M.; Lucas, R.; Mucher, C.A.; O'Connor, B.; Paganini, M.; Pereira, H.M.; et al. Agree on biodiversity metrics to track from space. Nature 2015, 523, 403-405. [CrossRef] [PubMed]

23. Ustin, S.L.; Gitelson, A.A.; Jacquemoud, S.; Schaepman, M.; Asner, G.P.; Gamon, J.A.; Zarco-Tejada, P. Retrieval of foliar information about plant pigment systems from high resolution spectroscopy. Remote Sens. Environ. 2009, 113, S67-S77. [CrossRef]

24. Wang, Z.; Chlus, A.; Geygan, R.; Ye, Z.; Zheng, T.; Singh, A.; Couture, J.J.; Cavender-Bares, J.; Kruger, E.L.; Townsend, P.A. Foliar functional traits from imaging spectroscopy across biomes in eastern North America. New Phytol. 2020, 228, 494-511. [CrossRef] [PubMed]

25. Schneider, F.D.; Morsdorf, F.; Schmid, B.; Petchey, O.L.; Hueni, A.; Schimel, D.S.; Schaepman, M.E. Mapping functional diversity from remotely sensed morphological and physiological forest traits. Nat. Commun. 2017, 8, 1441. [CrossRef]

26. Jacquemoud, S.; Ustin, S. Measurement of Leaf Optical Properties. In Leaf Optical Properties; Jacquemoud, S., Ustin, S., Eds.; Cambridge University Press: Cambridge, UK, 2019; pp. 74-123.

27. Jacquemoud, S.; Baret, F. PROSPECT: A model of leaf optical properties spectra. Remote Sens. Environ. 1990, 34, 75-91. [CrossRef]

28. Féret, J.B.; Gitelson, A.A.; Noble, S.D.; Jacquemoud, S. PROSPECT-D: Towards modeling leaf optical properties through a complete lifecycle. Remote Sens. Environ. 2017, 193, 204-215. [CrossRef]

29. Féret, J.B.; François, C.; Asner, G.P.; Gitelson, A.A.; Martin, R.E.; Bidel, L.P.R.; Ustin, S.L.; le Maire, G.; Jacquemoud, S. PROSPECT4 and 5: Advances in the leaf optical properties model separating photosynthetic pigments. Remote Sens. Environ. 2008, 112, 3030-3043. [CrossRef]

30. Féret, J.-B.; Berger, K.; de Boissieu, F.; Malenovský, Z. PROSPECT-PRO for estimating content of nitrogen-containing leaf proteins and other carbon-based constituents. Remote Sens. Environ. 2021, 252, 112173. [CrossRef] 
31. Verrelst, J.; Malenovský, Z.; Van der Tol, C.; Camps-Valls, G.; Gastellu-Etchegorry, J.-P.; Lewis, P.; North, P.; Moreno, J. Quantifying Vegetation Biophysical Variables from Imaging Spectroscopy Data: A Review on Retrieval Methods. Surv. Geophys. 2019, 40, 589-629. [CrossRef]

32. Malenovský, Z.; Homolová, L.; Lukeš, P.; Buddenbaum, H.; Verrelst, J.; Alonso, L.; Schaepman, M.E.; Lauret, N.; GastelluEtchegorry, J.-P. Variability and Uncertainty Challenges in Scaling Imaging Spectroscopy Retrievals and Validations from Leaves Up to Vegetation Canopies. Surv. Geophys. 2019, 40, 631-656. [CrossRef]

33. Allen, W.A.; Gausman, H.W.; Richardson, A.J.; Thomas, J.R. Interaction of isotropic light with a compact plant leaf. J. Opt. Soc. Am. 1969, 59, 1376-1379. [CrossRef]

34. Vilfan, N.; van der Tol, C.; Muller, O.; Rascher, U.; Verhoef, W. Fluspect-B: A model for leaf fluorescence, reflectance and transmittance spectra. Remote Sens. Environ. 2016, 186, 596-615. [CrossRef]

35. Vilfan, N.; Van der Tol, C.; Yang, P.Q.; Wyber, R.; Malenovsky, Z.; Robinson, S.A.; Verhoef, W. Extending Fluspect to simulate xanthophyll driven leaf reflectance dynamics. Remote Sens. Environ. 2018, 211, 345-356. [CrossRef]

36. Le Maire, G.; François, C.; Dufrêne, E. Towards universal broad leaf chlorophyll indices using PROSPECT simulated database and hyperspectral reflectance measurements. Remote Sens. Environ. 2004, 89, 1-28. [CrossRef]

37. Malenovský, Z.; Albrechtová, J.; Lhotáková, Z.; Zurita-Milla, R.; Clevers, J.G.P.W.; Schaepman, M.E.; Cudlín, P. Applicability of the PROSPECT model for Norway spruce needles. Int. J. Remote Sens. 2006, 27, 5315-5340. [CrossRef]

38. Greaves, B.L.; Spencer, R.D. An evaluation of spectroradiometry and multispectral scanning for differentiating forest communities. Aust. For. 1993, 56, 68-79. [CrossRef]

39. ABARES. Australia's Forests at a Glance 2019: With Data to 2017-2018; Australian Bureau of Agricultural and Resource Economics and Sciences: Canberra, Australia, 2019.

40. Butt, N.; Pollock, L.J.; McAlpine, C.A. Eucalypts face increasing climate stress. Ecol. Evol. 2013, 3, 5011-5022. [CrossRef]

41. Barry, K.M.; Newnham, G.J.; Stone, C. Estimation of chlorophyll content in Eucalyptus globulus foliage with the leaf reflectance model PROSPECT. Agric. For. Meteorol. 2009, 149, 1209-1213. [CrossRef]

42. Barry, K.M.; Newnham, G.J. Quantification of chlorophyll and carotenoid pigments in eucalyptus foliage with the radiative transfer model PROSPECT 5 is affected by anthocyanin and epicuticular waxes. In Proceedings of the Geospatial Science Research Symposium-GSR_2, Melbourne, Australia, 10-12 December 2012.

43. Atzberger, C.; Richter, K. Spatially constrained inversion of radiative transfer models for improved LAI mapping from future Sentinel-2 imagery. Remote Sens. Environ. 2012, 120, 208-218. [CrossRef]

44. Combal, B.; Baret, F.; Weiss, M.; Trubuil, A.; Macé, D.; Pragnère, A.; Myneni, R.; Knyazikhin, Y.; Wang, L. Retrieval of canopy biophysical variables from bidirectional reflectance: Using prior information to solve the ill-posed inverse problem. Remote Sens. Environ. 2003, 84, 1-15. [CrossRef]

45. Ali, A.M.; Darvishzadeh, R.; Skidmore, A.K.; Duren, I.v.; Heiden, U.; Heurich, M. Estimating leaf functional traits by inversion of Prospect: Assessing leaf dry matter content and specific leaf area in mixed mountainous forest. Int. J. Appl. Earth Obs. Geoinf. 2016, 45, 66-76. [CrossRef]

46. Sehgal, V.K.; Chakraborty, D.; Sahoo, R.N. Inversion of radiative transfer model for retrieval of wheat biophysical parameters from broadband reflectance measurements. Inf. Process. Agric. 2016, 3, 107-118. [CrossRef]

47. Zhu, X.; Skidmore, A.K.; Darvishzadeh, R.; Wang, T. Estimation of forest leaf water content through inversion of a radiative transfer model from LiDAR and hyperspectral data. Int. J. Appl. Earth Obs. Geoinf. 2019, 74, 120-129. [CrossRef]

48. Esteban, R.; Balaguer, L.; Manrique, E.; Rubio de Casas, R.; Ochoa, R.; Fleck, I.; Pintó-Marijuan, M.; Casals, I.; Morales, D.; Jiménez, M.S.; et al. Alternative methods for sampling and preservation of photosynthetic pigments and tocopherols in plant material from remote locations. Photosynth. Res. 2009, 101, 77-88. [CrossRef]

49. Gitelson, A.A.; Solovchenko, A. Generic Algorithms for Estimating Foliar Pigment Content. Geophys. Res. Lett. 2017, 44, 9293-9298. [CrossRef]

50. Gitelson, A.A.; Gritz, Y.; Merzlyak, M.N. Relationships between leaf chlorophyll content and spectral reflectance and algorithms for non-destructive chlorophyll assessment in higher plant leaves. J. Plant Physiol. 2003, 160, 271-282. [CrossRef]

51. Gitelson, A.A.; Keydan, G.P.; Merzlyak, M.N. Three-band model for noninvasive estimation of chlorophyll, carotenoids, and anthocyanin contents in higher plant leaves. Geophys. Res. Lett. 2006, 33, L11402. [CrossRef]

52. Gitelson, A.A.; Merzlyak, M.N. Signature Analysis of Leaf Reflectance Spectra: Algorithm Development for Remote Sensing of Chlorophyll. J. Plant Physiol. 1996, 148, 494-500. [CrossRef]

53. Gitelson, A.A.; Merzlyak, M.N. Remote estimation of chlorophyll content in higher plant leaves. Int. J. Remote Sens. 1997, 18, 2691-2697. [CrossRef]

54. Merzlyak, M.N.; Solovchenko, A.E.; Gitelson, A.A. Reflectance spectral features and non-destructive estimation of chlorophyll, carotenoid and anthocyanin content in apple fruit. Postharvest Biol. Technol. 2003, 27, 197-211. [CrossRef]

55. Datt, B. A New Reflectance Index for Remote Sensing of Chlorophyll Content in Higher Plants: Tests using Eucalyptus Leaves. J. Plant Physiol. 1999, 154, 30-36. [CrossRef]

56. Datt, B. Visible/near infrared reflectance and chlorophyll content in Eucalyptus leaves. Int. J. Remote Sens. 1999, 20, 2741-2759. [CrossRef]

57. Gitelson, A.A.; Zur, Y.; Chivkunova, O.B.; Merzlyak, M.N. Assessing Carotenoid Content in Plant Leaves with Reflectance Spectroscopy. Photochem. Photobiol. 2002, 75, 272-281. [CrossRef] 
58. Datt, B. Remote Sensing of Chlorophyll a, Chlorophyll b, Chlorophyll a $+\mathrm{b}$, and Total Carotenoid Content in Eucalyptus Leaves. Remote Sens. Environ. 1998, 66, 111-121. [CrossRef]

59. Gitelson, A.A.; Merzlyak, M.N.; Chivkunova, O.B. Optical Properties and Nondestructive Estimation of Anthocyanin Content in Plant Leaves. Photochem. Photobiol. 2001, 74, 38-45. [CrossRef]

60. Féret, J.-B.; François, C.; Gitelson, A.; Asner, G.P.; Barry, K.M.; Panigada, C.; Richardson, A.D.; Jacquemoud, S. Optimizing spectral indices and chemometric analysis of leaf chemical properties using radiative transfer modeling. Remote Sens. Environ. 2011, 115, 2742-2750. [CrossRef]

61. Wang, L.; Qu, J.J.; Hao, X.; Hunt, E.R. Estimating dry matter content from spectral reflectance for green leaves of different species. Int. J. Remote Sens. 2011, 32, 7097-7109. [CrossRef]

62. Couture, J.J.; Serbin, S.P.; Townsend, P.A. Spectroscopic sensitivity of real-time, rapidly induced phytochemical change in response to damage. New Phytol. 2013, 198, 311-319. [CrossRef]

63. Serbin, S.P.; Singh, A.; McNeil, B.E.; Kingdon, C.C.; Townsend, P.A. Spectroscopic determination of leaf morphological and biochemical traits for northern temperate and boreal tree species. Ecol. Appl. 2014, 24, 1651-1669. [CrossRef]

64. Beringer, J.; Hutley, L.B.; McHugh, I.; Arndt, S.K.; Campbell, D.; Cleugh, H.A.; Cleverly, J.; De Dios, V.R.; Eamus, D.; Evans, B.; et al. An introduction to the Australian and New Zealand flux tower network-OzFlux. Biogeosciences 2016, 13, 5895-5916. [CrossRef]

65. Karan, M.; Liddell, M.; Prober, S.M.; Arndt, S.; Beringer, J.; Boer, M.; Cleverly, J.; Eamus, D.; Grace, P.; Van Gorsel, E.; et al. The Australian SuperSite Network: A continental, long-term terrestrial ecosystem observatory. Sci. Total Environ. 2016, 568, 1263-1274. [CrossRef] [PubMed]

66. Keith, H.; Leuning, R.; Jacobsen, K.L.; Cleugh, H.A.; van Gorsel, E.; Raison, R.J.; Medlyn, B.E.; Winters, A.; Keitel, C. Multiple measurements constrain estimates of net carbon exchange by a Eucalyptus forest. Agric. For. Meteorol. 2009, 149, 535-558. [CrossRef]

67. Leuning, R.; Cleugh, H.A.; Zegelin, S.J.; Hughes, D. Carbon and water fluxes over a temperate Eucalyptus forest and a tropical wet/dry savanna in Australia: Measurements and comparison with MODIS remote sensing estimates. Agric. For. Meteorol. 2005, 129, 151-173. [CrossRef]

68. Heatwole, H.; Lowman, M.D.; Donovan, C.; McCoy, M. Phenology of Leaf-Flushing and macroarthropod abundances in canopies of eucalyptus saplings. Selbyana 1997, 18, 200-214.

69. Evans, J.R.; Vogelmann, T.C. Photosynthesis within isobilateral Eucalyptus pauciflora leaves. New Phytol. 2006, 171, 771-782. [CrossRef]

70. Savitzky, A.; Golay, M.J.E. Smoothing and Differentiation of Data by Simplified Least Squares Procedures. Anal. Chem. 1964, 36, 1627-1639. [CrossRef]

71. Förster, B.; Osmond, C.B.; Pogson, B.J. De Novo Synthesis and Degradation of Lx and V Cycle Pigments during Shade and Sun Acclimation in Avocado Leaves. Plant Physiol. 2009, 149, 1179-1195. [CrossRef]

72. Waterman, M.J.; Bramley-Alves, J.; Miller, R.E.; Keller, P.A.; Robinson, S.A. Photoprotection enhanced by red cell wall pigments in three East Antarctic mosses. Biol. Res. 2018, 51, 49. [CrossRef]

73. Jacquemoud, S.; Ustin, S.L.; Verdebout, J.; Schmuck, G.; Andreoli, G.; Hosgood, B. Estimating leaf biochemistry using the PROSPECT leaf optical properties model. Remote Sens. Environ. 1996, 56, 194-202. [CrossRef]

74. Willmott, C.J. On the validation of models. Phys. Geogr. 1981, 2, 184-194. [CrossRef]

75. Malenovský, Z.; Homolová, L.; Zurita-Milla, R.; Lukeš, P.; Kaplan, V.; Hanuš, J.; Gastellu-Etchegorry, J.-P.; Schaepman, M.E. Retrieval of spruce leaf chlorophyll content from airborne image data using continuum removal and radiative transfer. Remote Sens. Environ. 2013, 131, 85-102. [CrossRef]

76. Le Maire, G.; François, C.; Soudani, K.; Berveiller, D.; Pontailler, J.-Y.; Bréda, N.; Genet, H.; Davi, H.; Dufrêne, E. Calibration and validation of hyperspectral indices for the estimation of broadleaved forest leaf chlorophyll content, leaf mass per area, leaf area index and leaf canopy biomass. Remote Sens. Environ. 2008, 112, 3846-3864. [CrossRef]

77. Romero, A.; Aguado, I.; Yebra, M. Estimation of dry matter content in leaves using normalized indexes and PROSPECT model inversion. Int. J. Remote Sens. 2012, 33, 396-414. [CrossRef]

78. Féret, J.B.; le Maire, G.; Jay, S.; Berveiller, D.; Bendoula, R.; Hmimina, G.; Cheraiet, A.; Oliveira, J.C.; Ponzoni, F.J.; Solanki, T.; et al. Estimating leaf mass per area and equivalent water thickness based on leaf optical properties: Potential and limitations of physical modeling and machine learning. Remote Sens. Environ. 2019, 231, 110959. [CrossRef]

79. Spafford, L.; le Maire, G.; MacDougall, A.; de Boissieu, F.; Féret, J.-B. Spectral subdomains and prior estimation of leaf structure improves PROSPECT inversion on reflectance or transmittance alone. Remote Sens. Environ. 2021, 252, 112176. [CrossRef]

80. Jacquemoud, S.; Ustin, S. Spectroscopy of Leaf Molecules. In Leaf Optical Properties; Jacquemoud, S., Ustin, S., Eds.; Cambridge University Press: Cambridge, UK, 2019; pp. 48-73.

81. Fossen, T.; Cabrita, L.; Andersen, O.M. Colour and stability of pure anthocyanins influenced by pH including the alkaline region. Food Chem. 1998, 63, 435-440. [CrossRef]

82. Sharma, P.J.; Crowden, R.K. Anthocyanins in Some Eucalyptus Species. Aust. J. Bot. 1974, 22, 623-627. [CrossRef]

83. Woodgate, W.; Suarez, L.; van Gorsel, E.; Cernusak, L.A.; Dempsey, R.; Devilla, R.; Held, A.; Hill, M.J.; Norton, A.J. tri-PRI: A three band reflectance index tracking dynamic photoprotective mechanisms in a mature eucalypt forest. Agric. For. Meteorol. 2019, 272-273, 187-201. [CrossRef] 
84. Hu, X.; Tanaka, A.; Tanaka, R. Simple extraction methods that prevent the artifactual conversion of chlorophyll to chlorophyllide during pigment isolation from leaf samples. Plant Methods 2013, 9, 19. [CrossRef]

85. Holmes, M.G.; Keiller, D.R. Effects of pubescence and waxes on the reflectance of leaves in the ultraviolet and photosynthetic wavebands: A comparison of a range of species. Plant Cell Environ. 2002, 25, 85-93. [CrossRef]

86. Hueni, A.; Damm, A.; Kneubuehler, M.; Schläpfer, D.; Schaepman, M.E. Field and Airborne Spectroscopy Cross Validation-Some Considerations. IEEE J. Sel. Top. Appl. Earth Obs. Remote Sens. 2017, 10, 1117-1135. [CrossRef] 